Illinois State University

ISU ReD: Research and eData

Theses and Dissertations

$4-21-2020$

\title{
The Impact Of Anthropometric Measurements On Lactate Levels At Rest And During Exercise
}

Ashley Kristine Edwards

Illinois State University, ashleyedwards222@gmail.com

Follow this and additional works at: https://ir.library.illinoisstate.edu/etd

Part of the Human and Clinical Nutrition Commons

\section{Recommended Citation}

Edwards, Ashley Kristine, "The Impact Of Anthropometric Measurements On Lactate Levels At Rest And During Exercise" (2020). Theses and Dissertations. 1268.

https://ir.library.illinoisstate.edu/etd/1268

This Thesis is brought to you for free and open access by ISU ReD: Research and eData. It has been accepted for inclusion in Theses and Dissertations by an authorized administrator of ISU ReD: Research and eData. For more information, please contact ISUReD@ilstu.edu. 


\section{ASHLEY KRISTINE EDWARDS}

49 Pages

Objective: The purpose of this study was to evaluate the relationship between anthropometric measures with heart rates (HR) at specific blood lactate concentrations [bLa] during exercise.

Method: Participants and data for this study were collected by an orthopedic rehabilitation center in Central Illinois. Participants underwent lactate testing following METHOD CRA protocol on an upright cycle and an optional DEXA scan. Heart rate values at Prime (2 mmol/L), Anaerobic (4 mmol/L) and Peak (6 mmol//L) blood lactate concentrations were recorded. Data was analyzed using Pearson correlations.

Results: A total of 59 participants were included. Participants ages ranged from $21-74$ years old and had on average a BMI of $34.3 \mathrm{~kg} / \mathrm{m}^{2}(\mathrm{SD}=8.34), \mathrm{WC}$ of 104.9 centimeters $(\mathrm{SD}=$ 22.1), and WHtR of $0.61(\mathrm{SD}=.012)$. The study found a statistically significant negative correlation between $\mathrm{PR}_{\mathrm{HR}}$ and $\mathrm{WC}(p=.020)$ as well as $\operatorname{PR}_{\mathrm{HR}}$ and $\mathrm{WHtR}(p=.030)$.

Conclusion: There was a stronger negative relationship between WC and WHtR with $\mathrm{PR}_{\mathrm{HR}}$ than there was with BMI Other variables approaching significance in this sample include a negative relationship between both $\mathrm{WC}$ and $\mathrm{WHtR}$ with $\mathrm{AN}_{\mathrm{HR}}$. This indicates that central adiposity may have a stronger connection with HR values at a specific lactate level during aerobic and anaerobic exercise that cannot be indicated with BMI alone. 
KEYWORDS: Waist Circumference (WC); Waist-to-height ratio (WHtR); body fat percent;

lactate; METHOD CRA 
REST AND DURING EXERCISE

ASHLEY KRISTINE EDWARDS

A Thesis Submitted in Partial

Fulfillment of the Requirements

for the Degree of

MASTER OF SCIENCE

Department of Family and Consumer Sciences

ILLINOIS STATE UNIVERSITY 
(C) 2020 Ashley Kristine Edwards 
THE IMPACT OF ANTHROPOMETRIC MEASUREMENTS ON LACTATE LEVELS AT

REST AND DURING EXERCISE

ASHLEY KRISTINE EDWARDS

COMMITTEE MEMBERS:

Jennifer Barnes, Chair

Dale Brown

Luke Russell 


\section{ACKNOWLEDGMENTS}

I would like to thank all the faculty and staff of Family and Consumer Sciences for making me feel welcome and providing me the knowledge and support necessary to complete this thesis. I owe my deepest gratitude to Dr. Barnes for having enormous patience and being understanding with me. I truly appreciate your time and guidance through this process. To Dr. Brown and Dr. Russell, thank you for providing valuable insight in research design, narrowing my purpose, and how to avoid errors while conducting my research.

I would also like to thank the staff at McLean County Orthopedics. This thesis would not have been possible without your help, support, and resources. To Karina Robles, thank you so much for answering my many questions and dedicating your time to help me with my research. You were always kind and willing to lend your support.

Finally, I could never express how grateful I am for my family and friends. To my parents, I can never repay you for your support and lost nights together. To my brother, Eddie, thank you for instilling the desire to learn and drive for continual improvement. I would not be the person I am today without your impact on my life and your loss, which came far too early. To Sean Pavlick, you are incredible for reading and re-reading lengthy drafts; enduring through my senseless stress, anxiety, and loud noises; facilitating stimulating conversations to help with my writing; and always lending your love and support.

A. K. E 


\section{CONTENTS}

Page

ACKNOWLEDGMENTS

TABLES

FIGURES

CHAPTER I: THE IMPACT OF ANTHROPOMETRIC MEASUREMENTS ON LACTATE

LEVELS AT REST AND DURING EXERCISE 1

$\begin{array}{ll}\text { Introduction } & 1\end{array}$

$\begin{array}{ll}\text { Methodology } & 3\end{array}$

Study Population $\quad 3$

$\begin{array}{ll}\text { Measures } & 4\end{array}$

METHOD CRA Test

$\begin{array}{ll}\text { Statistical Analysis } & 6\end{array}$

$\begin{array}{ll}\text { Results } & 6\end{array}$

$\begin{array}{ll}\text { Discussion } & 7\end{array}$

$\begin{array}{ll}\text { Limitations } & 13\end{array}$

$\begin{array}{ll}\text { Future Studies } & 14\end{array}$

$\begin{array}{ll}\text { Conclusion } & 14\end{array}$

CHAPTER II: REVIEW OF THE LITERATURE 24

Anthropometric Measurement Accuracy and Relationship to Health-Related Outcomes 24

$\begin{array}{ll}\text { Body Mass Index (BMI) } & 24\end{array}$

$\begin{array}{ll}\text { Body Fat Percentage } & 24\end{array}$

$\begin{array}{ll}\text { Waist Circumference } & 26\end{array}$ 
Waist to Height Ratio (WHtR)

$\begin{array}{ll}\text { Body Fat and DEXA } & 27\end{array}$

$\begin{array}{ll}\text { Anthropometrics and Exercise Performance } & 28\end{array}$

BMI and Exercise Performance 28

Abdominal Adiposity and Exercise Performance 29

Metabolically Healthy Obese and Metabolically Obese Normal Weight 30

Role of Lactate in the Body $\quad 32$

Lactate Formation $\quad 32$

Lactate Accumulation During Exercise 33

Lactate as an Energy System Indicator $\quad 34$

$\begin{array}{ll}\text { Lactate and Fatigue } & 34\end{array}$

$\begin{array}{ll}\text { Lactate Clearance } & 35\end{array}$

Metabolic Diseases and Disorders Impact on Lactate 36

Adipose Tissue and Lactate $\quad 36$

Obesity and Resting Lactate $\quad 38$

Impaired Glucose Metabolism and Lactate $\quad 38$

Lactate Testing $\quad 39$

Method CRA Testing $\quad 39$

$\begin{array}{ll}\text { REFERENCES } & 41\end{array}$ 


\section{TABLES}

Table

Page

1. Participant demographics

2. Table of correlations

3. Demographics of DEXA participants

4. Table of correlations for DEXA participants 


\section{FIGURES}

Figure

Page

1. Body Mass Index (BMI) and Resting Blood Lactate Concentration

2. Body Mass Index (BMI) and Prime Heart Rate $\left(\mathrm{PR}_{\mathrm{HR}}\right)$

3. Body Mass Index (BMI) and Anaerobic Heart Rate $\left(\mathrm{AN}_{\mathrm{HR}}\right)$

4. Waist Circumference (WC) and Resting Blood Lactate Concentration

5. Waist Circumference (WC) and Prime Heart Rate $\left(\mathrm{PR}_{\mathrm{HR}}\right)$

6. Waist Circumference (WC) and Anaerobic Heart Rate $\left(\mathrm{AN}_{\mathrm{HR}}\right)$

7. Waist to Height Ratio (WHtR) and Resting Blood Lactate Concentration

8. Waist to Height Ratio (WHtR) and Prime Heart Rate $\left(\mathrm{PR}_{\mathrm{HR}}\right)$

9. Waist to Height Ratio (WHtR) and Anaerobic Heart Rate ( $\left.\mathrm{AN}_{\mathrm{HR}}\right)$

10. Body Fat Percent (BF\%) and Resting Blood Lactate Concentration

11. Body Fat Percent $(\mathrm{BF} \%)$ and Prime Heart Rate $\left(\mathrm{PR}_{\mathrm{HR}}\right)$

12. Body Fat Percent (BF\%) and Anaerobic Heart Rate $\left(\mathrm{AN}_{\mathrm{HR}}\right)$ 


\section{CHAPTER I: THE IMPACT OF ANTHROPOMETRIC MEASUREMENTS ON LACTATE}

\section{LEVELS AT REST AND DURING EXERCISE}

\section{Introduction}

Body Mass Index (BMI) has been the standard for assessing health status and body fatness. Arguments for its use include the relative ease and low cost associated with collecting the measurement. Even though it is a highly regarded measurement, BMI only looks at two measures: height and weight. This assumes that there is no difference in the relationship between height and weight at any age, fitness level, gender, or ethnicity. Several studies have demonstrated the differences in body fat percentage (BF\%) that come with these factors (Akindele et al., 2016; McArdle et al., 2015). Furthermore, BMI is unable to differentiate between excess fat mass, muscle mass, or bone mass, which also varies among populations. Other anthropometric measures can be obtained just as easily. Waist circumference (WC) and waist-to-height ratio (WHtR) only require a single tape measure and are simple to interpret. They allow health care professionals to quickly identify individuals with high levels of central adiposity. In general, a high BF\% poses negative health risks, but central adiposity may pose even greater health risks and decreased physical performance than BMI alone (Kang et al., 2011; Mikkola et al., 2018; Ross et al., 2020).

Body composition has an impact on physical performance (McArdle et al, 2015). Past researchers have found a negative relationship between abnormal anthropometric measures and exercise performance (Monda \& Mishra, 2017; Minasian et al., 2014; Arriscado et al., 2014). However, these studies typically focus on maximal oxygen uptake (VO2max) and other indicators to measure such performance. Measuring blood lactate concentration ([bLa]) and heart rate $(\mathrm{HR})$ during incremental exercise tests is another common practice used to evaluate physical 
performance. Lactate testing is used to determine personal aerobic lactate thresholds and anaerobic lactate thresholds. In order to optimize training, individuals should strive to exercise at a HR reflective of their aerobic lactate threshold where they are utilizing fats as their primary energy source (Fraude et al., 2009). At this rate, aerobic energy systems are dominant, allowing training for an extended period with avoidance of early fatigue (Bircher et al., 2005).

Athletes are not the only population that can benefit from lactate testing to determine overall fitness and training zones. Individuals completing various physical therapies such as orthopedic or cardiopulmonary therapy, or inactive adults starting an exercise regimen, can also benefit from lactate testing. When prescribing exercise programs in these populations, trainers must be cautious to ensure subjects are not being overworked or tiring too quickly. Unfortunately, lactate testing is less widely practiced and studied in this population.

There are various approaches and techniques to lactate testing. The current study focused on the METHOD Cellular Respiration and Analytics (CRA) test. This is an incremental exercise test where HR and [bLa] are measured periodically providing participants with Prime, Anaerobic, and Peak heart rate zones indicative of different energy systems and fuel source utilization. The Prime heart rate $\left(\mathrm{PR}_{\mathrm{HR}}\right)$, measured at $2 \mathrm{mmol} / \mathrm{L}[\mathrm{bLa}]$, is the point where the body is burning the greatest amount of fat as a fuel source. At the Anaerobic heart rate zone (AN $\mathrm{HR}_{\mathrm{HR}}$, measured at $4 \mathrm{mmol} / \mathrm{L}[\mathrm{bLa}]$, the body is almost exclusively utilizing stored carbohydrates as its main fuel. Peak heart rate $\left(\mathrm{PK}_{\mathrm{HR}}\right)$ is measured at $6 \mathrm{mmol} / \mathrm{L}[\mathrm{bLa}]$ or greater and reflects a point in exercise where the body is depleted of energy sources. Exercising at $\mathrm{PK}_{\mathrm{HR}}$ can significantly decrease performance and increase the risk of injury.

There are many complex factors involved when investigating lactate levels, exercise capability, and heart rate during exercise. There is a lack of research examining the relationship 
between anthropometric measures and $\mathrm{HR}$ values at specific lactate levels at rest, $\mathrm{P}_{\mathrm{HR}}$, and $\mathrm{AN}_{\mathrm{HR}}$. It is not unreasonable to assume that there could be a relationship between anthropometric measures and blood lactate levels at rest and during exercise. This study aims to evaluate the relationship between $\mathrm{BMI}, \mathrm{WC}, \mathrm{WHtR}$, and $\mathrm{BF} \%$ with resting lactate, $\mathrm{P}_{\mathrm{HR}}$, and $\mathrm{AN}_{\mathrm{HR}}$. It is hypothesized that $\mathrm{WC}, \mathrm{WHtR}$, and $\mathrm{BF} \%$ will influence resting lactate, $\mathrm{PR}_{\mathrm{HR}}$, and $\mathrm{AN}_{\mathrm{HR}}$. It is further hypothesized that BMI will have the weakest impact and BF\% will have the strongest impact resting lactate, $\mathrm{PR}_{\mathrm{HR}}$, and $\mathrm{AN}_{\mathrm{HR}}$.

\section{Methodology}

\section{Study Population}

\section{Recruitment}

Data for this study was collected from a deidentified patient database created by an orthopedic rehabilitation center in Central Illinois. The center enlists patients into their program on a rolling basis and records patient results in a deidentified excel spreadsheet for data analysis and research purposes. Permission was obtained to use this data from the center. Permission was also obtained to reference METHOD CRA from the company founders. This study was approved by the Institutional Review Board (IRB) of Illinois State University.

Patients were included in the spreadsheet by rehabilitation center staff members if they are enrolled in formal physical therapy or the body composition program offered by the company and they have agreed to participate in the study. Participants were provided with details related to the study, including the METHOD Information Handout for the exercise test. To determine the participant's ability to complete the exercise test for the study program they first completed a Physical Readiness Questionnaire. Physician clearance was obtained if a participant answered "yes" to any of the questions before performing the test. Before starting the study, participants 
read and signed an informed consent. Participants also provided verbal consent for participation in the METHOD CRA and DEXA tests.

\section{Inclusion Criteria}

This study was restricted to adults 18 years or older who fully completed anthropometric measurements, and METHOD CRA testing. This study also included participants who completed an optional DEXA scan in addition to anthropometric measures and METHOD CRA testing. Further inclusion criteria included: having values for the following variables: height, weight, sex, age, waist circumference, body fat percent, $\mathrm{PR}_{\mathrm{HR}}, \mathrm{AN}_{\mathrm{HR}}$, and resting lactate levels. Participants were excluded if: they were currently taking beta blockers, are insulin dependent, if BMI was < $18.5 \mathrm{~kg} / \mathrm{m}^{2}$, METHOD CRA testing was not conducted on an upright cycle, or if it was not the participant's first time completing a METHOD CRA test.

\section{Measures}

Relevant measures related to the current study were obtained from an orthopedic rehabilitation center deidentified patient database. All measures were taken and recorded by trained rehabilitation center staff members. Height was measured using a Health-O-Meter Professional weigh scale model $500 \mathrm{KL}$ with height rod. Weight was measured at a standing position with shoes removed on the same scale. Waist circumference was measured in centimeters according to American College of Sports Medicine (ACSM) protocol with patient standing using nonelastic tape. Body fat percentage was measured via entire body Hologic Horizon DEXA scan following the rehabilitation center DEXA protocol. After removal of shoes and outerwear, participants were provided with a clean gown and privacy to change before completing the scan. Blood lactate concentrations were collected during METHOD CRA test as described below. 


\section{METHOD CRA Test}

CRA testing procedure followed guidelines from the METHOD manual regarding how to collect samples and time of sample collection. Each participant completed the CRA exercise test using a Matrix 3x upright cycle, model Hure-3X-O2-C. Blood lactate samples were measured with a Nova Biomedical Lactate Plus Meter. Blood samples were collected using a lancet to acquire a small blood sample from the earlobe onto a blood lactate testing strip.

For HR monitoring, Polar H7 or Polar H10 HR monitors were utilized. Participants could use their own HR monitors, or they were provided a HR monitor by rehabilitation center staff. Resting HR was obtained from HR monitors after participants had been lying supine for a minimum of two minutes. All measures were recorded onto a printed copy of the CRA Recording Form by the rehabilitation center staff member. METHOD CRA provides two numbers for $\mathrm{PR}_{\mathrm{HR}}$ range. The low end of the range was used as $\mathrm{PR}_{\mathrm{HR}}$ for the purposes of this study and is the $\mathrm{HR}$ at a [bLa] of $2 \mathrm{mmol} / \mathrm{L}$. $\mathrm{AN}_{\mathrm{HR}}$ was the $\mathrm{HR}$ recorded at a [bLa] of $4 \mathrm{mmol} / \mathrm{L}$.

The upright cycle was fitted to the participant so that there was a 15 -20-degree bend in the knee with the pedal down and the participant could comfortably make a revolution. The test was individualized based on medical history and data collected before the start of the test. Participants started at an initial workload of 15-watts. After a three-minute warm up, [bLa] and heart rate were collected every subsequent three minutes, followed by a 15 -watt increase in workload. Heart rate values at Prime $(2 \mathrm{mmol} / \mathrm{L})$, Anaerobic $(4 \mathrm{mmol} / \mathrm{L})$ and Peak $(6 \mathrm{mmol} / / \mathrm{L})$ lactate concentrations were recorded. Once the participant reached a [bLa] of 6-7 $\mathrm{mmol}$ the test was terminated. Additionally, the test could be terminated at any time by the request of the participant, if the clinician deemed continuation of the test unsafe or not necessary, or if two consecutive lactate samples failed to show an increase in blood lactate levels. 
Participants classified as significantly deconditioned followed a separate protocol. Participants were categorized as significantly deconditioned if they met any two out of four criteria: $\mathrm{BMI}>40$, resting HR greater than $90 \mathrm{bpm}$, resting [bLa] greater than $1.5 \mathrm{mmol} / \mathrm{L}$, or had a diagnosis of heart disease or diabetes by a physician. Significantly deconditioned participants started at an initial workload of 5-watts. Workload was increased by 5 -watts every three minutes until a 15-watt workload was reached. After the 15-watt workload was reached, following intervals were increased by 10 -watts until the test was completed. Sampling of [bLa] and workload increases continued in three-minute intervals.

\section{Statistical Analysis}

Data was analyzed using Microsoft Excel version 2003 (Build 12624.20382) software program. Data was analyzed as a full group and as a DEXA subgroup. The relationships among anthropometric measures (BMI, WC, WHtR, and BF\%) with METHOD CRA (resting blood lactate, $\mathrm{PR}_{\mathrm{HR}}$, and $\mathrm{AN}_{\mathrm{HR}}$ ) results will be calculated using Pearson's correlation analysis. A pvalue $<0.05$ and the critical value of Pearson's correlation coefficient was used to determine statistical significance of correlations.

\section{Results}

This study investigated the relationship between anthropometric measures with resting lactate, $\mathrm{PR}_{\mathrm{HR}}$, and $\mathrm{AN}$ HR. Table 1 describes the demographics of the sample. A total of 59 participants were included in the study. Of the 59 participants, 24 (41\%) were male and 35 (59\%) were female. Participant ages ranged between 21-74 years old, with an average age of 48.5 years $(\mathrm{SD}=13.2)$. The predominant ethnicity of this population was white, with one Asian participant, and one Hispanic participant. Average BMI was calculated to be $34.3 \mathrm{~kg} / \mathrm{m}^{2}$ ( $\mathrm{SD}=8.34$ ), which is 
categorized as an obese BMI. The average WC and WHtR of the participants were 104.9 centimeters $(\mathrm{SD}=22.1)$ and $0.61(\mathrm{SD}=.012)$, respectively.

Table 2 displays the correlations of this study's main variables when accounting for all participants. The alpha value was set at .05 to determine the significance of the correlation between variables using critical values for Pearson's correlation coefficient. There was a statistically significant negative correlation between $\operatorname{PR}_{\mathrm{HR}}$ and $\mathrm{WC}(p=.020)$ as well as $\mathrm{PR}_{\mathrm{HR}}$ and WHtR $(p=.030)$ (Table 2$)$. A few variables were approaching statistical significance. Resting [bLa] and BMI $(p=.089)$ had a positive relationship, while $\mathrm{PR}_{\mathrm{HR}}$ and BMI were found to have a negative relationship $(p=.097)$ (Table 2).

This study also aimed to evaluate the relationship between BF\% and resting [bLa], $\mathrm{PR}_{\mathrm{HR}}$, and $\mathrm{AN}_{\mathrm{HR}}$. Not all participants in the study received DEXA scans. Table 3 displays the demographics for DEXA participants. There was no statistically significant difference between the DEXA sample group and the sample as far as age, BMI, WC, and WHtR. There was a total of 15 participants, with averages of $49.9(\mathrm{SD}=10.49)$ years old, $\mathrm{BMI}$ of $30.9 \mathrm{~kg} / \mathrm{m}^{2}(\mathrm{SD}=6.01)$, WC of 99.6 centimeters $(\mathrm{SD}=14.47)$, WHtR of $0.58(\mathrm{SD}=.08)$, and $\mathrm{BF} \%$ of $38.4 \%(\mathrm{SD}=$ 8.64) (Table 4). Results did not show any statistically significant relationships; however, a few relationships were approaching significance. $B F \%$ and $\operatorname{PR}_{\mathrm{HR}}(p=.090)$ had a negative relationship, while WHtR and resting $[\mathrm{bLa}](p=0.087)$ and $\mathrm{BF} \%$ and resting $[\mathrm{bLa}](p=.0101)$ had a positive relationship (Table 4). Figures 1 - 12 provide a visualization of the relationship between each anthropometric measurement with resting lactate, $\mathrm{PR}_{\mathrm{HR}}$, and $\mathrm{AN}_{\mathrm{HR}}$.

\section{Discussion}

The purpose of this study was to evaluate the relationship between BMI, WC, WHtR, and $\mathrm{BF} \%$ with HR values reflective of Prime and Anaerobic [bLa] levels during exercise. This is to 
analyze the thought that there may be more to the picture than just an individual's BMI classified weight status. Correlational analysis was used to determine the relationship between BMI, WC, $\mathrm{WHtR}$, and $\mathrm{BF} \%$ with resting [bLa], $\mathrm{PR}_{\mathrm{HR}}$, and $\mathrm{AN}_{\mathrm{HR}}$. The primary findings of this study indicate that WC and WHtR have a stronger relationship with the dependent variables than BMI. Participant demographics predominately reflect a white, middle-aged population. The majority in this sample were white, decreasing the chance for variance that comes with different ethnic backgrounds. The average BMI of the sample was $34.3 \mathrm{~kg} / \mathrm{m}^{2}$, which is classified as obese. Of the 59 participants, only eight were BMI-classified as normal weight. The average WC of participants was $104.9 \mathrm{~cm}$, which is classified as having a very high adverse health risk as values are greater than $102 \mathrm{~cm}$ for men and $88 \mathrm{~cm}$ for women (Lohman \& Milliken, 2020; Matsuzawa \& Despres, 2020). The WHtR of this sample is also categorized at an increased heath risk. All averages were greater than 55\% which is above the cut off indicative of an increased risk for metabolic diseases (Ashwell et al., 2012).

In addition, the subgroup that participated in DEXA scans $(n=15)$, who were not found to be statistically different from the total sample, had an average male and female BF\% of $31.7 \%$ and $42.8 \%$, respectively (Table 4). In addition, the BF\% of both male and female participants are considered very high for their age and sex (Akindele et al., 2016). Overall, this sample would not be considered a healthy population with regards to their anthropometric measures. Unfortunately, the activity status of participants was not available for assessment, but it may be hypothesized that as a whole these participants are not consistently partaking in exercise.

The current study found a statistically significant negative correlation via the critical value of Pearson's correlation coefficient between $\mathrm{PR}_{\mathrm{HR}}$ and $\mathrm{WC}$, as well as $\mathrm{PR}_{\mathrm{HR}}$ and WHtR when viewing the total sample group (Table 2). The finding that only WC and WHtR showed a 
statistically significant negative correlation with $\mathrm{PR}_{\mathrm{HR}}$ in this sample may have several explanations. When looking at a greater than normal WC, we can accurately judge the elevation is related to increase adipose tissue storage. However, with BMI, we cannot accurately decide if the elevated number is from muscle mass or fat mass. It is also unlikely to store excessive amount of muscle around the abdomen. For the participants in the current study, we can assume that they have an above average adipose tissue storage.

This increase in adipose tissue may be causing participants to produce more lactate than participants with less adipose tissue. While exercising, some cells may be experiencing anaerobic conditions even if the whole body is not yet exercising anaerobically. There is evidence to support the idea that adipocytes can produce lactate when in anaerobic conditions (Proia et al., 2016). When oxygen is not available, adipocytes can utilize glycolytic metabolism producing lactate in amounts proportional to the amount of adipose tissue (Perez de Heredia et al., 2010; Proia et al., 2016). Therefore, it is plausible that participants were experiencing additional lactate production causing them to reach $\mathrm{PR}_{\mathrm{HR}}$ faster than leaner participants.

In addition to an above average adipose storage, it is also known that the location of adipose tissue is around the waist, considered visceral adipose tissue. Adipose tissue in this area has been shown to be capable of greater rates of glucose to lactate metabolism that may be up to two or three times greater than levels produced in other areas of fat storage in the body (Digirolamo et al, 1992). With this information, an individual with an elevated WC, but normal BMI, may be producing more lactate due to central adiposity stores than another individual with the same BMI, but smaller WC. This may cause individuals with a higher WC, and WHtR, to have higher resting lactate levels than someone with lower measures, which in turn could explain why there is a statistically significant negative correlation between WC and WHtR with $\mathrm{PR}_{\mathrm{HR}}$ as 
participants were reaching $[\mathrm{bLa}]$ of $2 \mathrm{mmol} / \mathrm{L}$ quicker than participants with lower $\mathrm{WC}$ and WHtR.

These findings align with the findings of previous studies which investigated the relationship between WC and physical fitness and performance. Dyrstad et al. (2019) evaluated cardiorespiratory fitness (CRF) via $\mathrm{VO}_{2 \max }$ in men and women of various $\mathrm{WC}$ risk groups during a progressive graded treadmill test finding a high negative correlation between CRF and WC in men and a moderate correlation in women. Another study conducted by Shioya-Yamada et al. (2018) investigated the association between visceral fat accumulations and exercise tolerance in non-obese participants finding visceral fat to be significantly negatively correlated with exercise tolerance. Although these studies are not assessing exercise tolerance using the same method as the current study, they are measuring similar aspects leading to reflect overall fitness levels. Individuals with higher WC are less able than lower WC individuals to perform exercise. In addition to the contribution to increased lactate production, increased WC and WHtR may also reduce pulmonary function making breathing more difficult. Insufficient respiration could potentially cause a lack of adequate oxygen supply to tissues causing anaerobic metabolism to initiate quicker than in an individual maintaining normal pulmonary functionality.

Furthermore, it is important to note the small sample size. It is theorized that a larger sample size may allow for greater differences to be seen in the data. It is also important to keep in mind that these correlations may be inflated due to the smaller sample size. In addition, although there may be statistical significance, the data may not have enough power to show clinical significance. Even though the correlations may still be valid, statistical power is lost with a small sample size. 
It is interesting that $\mathrm{PR}_{\mathrm{HR}}$ was statistically negatively correlated with $\mathrm{WC}$ and $\mathrm{WHtR}$ in the full sample but was not significantly correlated with $\mathrm{AN}_{\mathrm{HR}}$ as the two should be highly correlated themselves. It is possible more variables come into play with $\mathrm{PR}_{\mathrm{HR}}$ and $\mathrm{AN}_{\mathrm{HR}}$. $\mathrm{PR}_{\mathrm{HR}}$ is indicative of aerobic metabolism were fatty acids are the primary source of fuel. However, in anaerobic metabolism, carbohydrates become the primary fuel source. In obese individuals with high WC and WHtR, their decreased cardiorespiratory fitness may have a stronger impact on their ability to partake in physical activity and maintain aerobic exercise causing the stronger correlation between $\mathrm{PR}_{\mathrm{HR}}$ than with $\mathrm{AN}_{\mathrm{HR}}$. Furthermore, other researchers have found obese individuals to have lower maximal fat oxidation rates than athletes, and increased rates of carbohydrate oxidation rates (Bircher \& Knechtle, 2004). This may be further impacting the $\mathrm{PR}_{\mathrm{HR}}$ and $\mathrm{AN}_{\mathrm{HR}}$ of the primarily obese subjects in this current study. More research is needed to elaborate on this topic. Additional information on participant activity level may also help explain these results as increased fitness can increase lactate threshold and anaerobic threshold. Another possibility impacting the results may be due to participants reaching $\mathrm{PR}_{\mathrm{HR}}$ faster at the start of the test, then settling into the exercise protocol as testing continued. Deconditioned participants may start the test at a higher resting [bLa] causing them to reach $\mathrm{PR}_{\mathrm{HR}}$ more quickly. As they settled in, [bLa] may not be accumulating as quickly as in the beginning of the test.

In contrast, BMI was not found to have a statistically significant correlation with $\mathrm{PR}_{\mathrm{HR}}$. BMI was approaching statistical significance in relation to $\mathrm{PR}_{\mathrm{HR}}$ in the total sample. This may be due to the inherit relationship between WC and BMI as it is expected that with a larger WC or WHtR, BMI will also be elevated. However, this lack of a statistically significant relationship in this sample further demonstrates the idea that BMI may not be as informative for identifying health risks or fitness level as WC or WHtR. This finding supports the researcher's hypothesis 
that BMI would not be as strongly correlated as other anthropometrics which provide an idea of fat distribution than BMI. This finding may also further the discussion of metabolically obesenormal weight (MONW) individuals. Given the fact that you can have an elevated WC or WHtR, but a classified as a health weight via BMI, can decrease someone's physical performance and [bLa] levels during exercise.

The current study did not find BMI to be statistically significantly correlated with the dependent variables. However, BMI may have been approaching statistical significance with resting $[\mathrm{bLa}]$ in the full sample $(p=.111)$. It was expected to find a relationship between BMI, WC, WHtR, and BF\% with resting [bLa] with the relationship being weakest with BMI. This comes with the idea that an increased BMI typically is due to an increase in adiposity causing disruption in glucose metabolism and possible increase production of lactate at rest.

The DEXA subgroup consisted of only 15 participants. Unfortunately, very few participants partook in DEXA scans. DEXA participants also had a large age range (36 - 50 years) and BMI range $\left(22.8-40.5 \mathrm{~kg} / \mathrm{m}^{2}\right)$. The participants had an elevated average $\mathrm{BF} \%$ as a group, and when grouped by sex, with an average BF\% of 38.4\% (Table 3). Although there were no statistically significant correlations in this group, $\mathrm{BF} \%$ and $\mathrm{PR}_{\mathrm{HR}}$ may have been approaching significant negative correlation $(p=.090, \mathrm{r}=-.453)$ (Table 4). It was hypothesized that BF\% would be more strongly correlated than BMI with $\mathrm{PR}_{\mathrm{HR}}$ and $\mathrm{AN}_{\mathrm{HR}}$. In theory, this hypothesis was justified as BF\% did have a stronger Pearson's r value with both $\mathrm{PR}_{\mathrm{HR}}$ and $\mathrm{AN}_{\mathrm{HR}}$ than was seen with BMI even though it was not significant. The findings in the current study are similar to those in a study by Sung et al. (2016) which found participants with higher BF\% to have higher [bLa] values immediately after intense exercise, and after several minutes of rest when compared to a healthy group with similar resting [bLa] levels. Participants in the current study reached 
[bLa] levels of $2 \mathrm{mmol} / \mathrm{L}$ and $4 \mathrm{mmol} / \mathrm{L}$ at a lower $\mathrm{HR}$ with higher $\mathrm{BF} \%$. This may also be due to their decreased ability to clear lactate, as with the higher BF\% individuals in the study in 2016 by Sung et al. The changes in metabolism that come with increased levels of BF\% may also contribute to the negative relationship between $\mathrm{BF} \%$ and $\mathrm{PR}_{\mathrm{HR}}$ and $\mathrm{AN}_{\mathrm{HR}}$. A study conducted in rats found obese rats to have faster rates of lactate accumulation and decreased levels of lactate transporter proteins decreasing lactate uptake in the liver (Chet et al., 2017). Overall, several metabolic and physical functionality changes may be contributing to the negative relationship between these variables.

\section{Limitations}

This study had multiple limitations. One limitation mentioned previously is the small sample size. Not only does the small sample size decrease the ability to detect differences between groups, it also may be falsely inflating the correlations between variables. It is also important to note that even though some correlations were statistically significant, the Pearson- $r$ values were not particularly large enough to indicate strong or moderate relationships. Additional limitations include the unknown current fitness level of participants. Many participants in the study participated as it was free through their medical insurance, while it is possible that some participants were walk-ins and paid to have testing done. The data in this study was not collected by the researcher, decreasing the amount of information the researcher can collect on participants. Other issues with the sample were the demographics. This was a small sample of predominately obese individuals. If there were more participants of varying BMI classifications in the study, it would lend more statistical power and ability to possibly see more differences and relationships through correlations. Furthermore, it is important to note that statistical significance does not always lend clinical significance. Although statistical significance was found between 
some variables, they are still weak correlations that may not attribute to clinical significance based of this current sample and study.

\section{Future Studies}

There are many avenues that can be investigated in future studies. More studies are needed to evaluate the relationship between anthropometric measures and lactate testing in obese or overweight individuals who are not athletes. Further studies could elaborate on the current study by including more participants of varying BMI classifications (Normal weight, overweight, and metabolically healthy obese) to determine the relationship between anthropometric measures and [bLa] at $2 \mathrm{mmol} / \mathrm{L}$ and $4 \mathrm{mmol} / \mathrm{L}$. It would also be beneficial to determine the current activity and fitness level of participants to further divide participants based on fitness categories. A study including fat free mass and BF\% could also be beneficial to further evaluate the relationship.

\section{Conclusion}

This study is one of the few to evaluate lactate thresholds at $2 \mathrm{mmol} / \mathrm{L}\left(\mathrm{PR}_{\mathrm{HR}}\right)$ and 4 $\mathrm{mmol} / \mathrm{L}\left(\mathrm{AN}_{\mathrm{HR}}\right)$ in a predominately obese population. Furthermore, the current study is one of the few to evaluate the relationship between BMI, WC, WHtR, and BF\% on resting [bLa] and lactate during exercise. The aim of this study was to investigate the relationship between other measures of adiposity distribution with [bLa] to determine if they are correlated with resting blood lactate, $\mathrm{HR}$ at $2 \mathrm{mmol} / \mathrm{L}$ [bLa] $\left(\mathrm{PR}_{\mathrm{HR}}\right)$, and $\mathrm{HR}$ at $4 \mathrm{mmol} / \mathrm{L}$ [bLa] $\left(\mathrm{AN}_{\mathrm{HR}}\right)$. From the evidence indicated by the Pearson correlation coefficient analysis, there was a stronger negative relationship between $\mathrm{WC}$ and $\mathrm{WHtR}$ with $\mathrm{PR}_{\mathrm{HR}}$ than was seen with $\mathrm{BMI}$ and $\mathrm{PR}_{\mathrm{HR}}$. Other variables approaching significance include the negative relationships of WC and WHtR with 
$\mathrm{AN}_{\mathrm{HR}}$. This indicates that central adiposity has a stronger connection with lactate levels during aerobic and anaerobic exercise that cannot be found with BMI alone. 
Table 1

Participant demographics

\begin{tabular}{llllc}
\hline Measurement & Male $(\mathbf{n}=\mathbf{2 4})$ & Female $(\mathbf{n = 3 5})$ & Total $(\mathbf{n = 5 9})$ & $\boldsymbol{p}$ value \\
\hline Age $($ years) & $45.6(14.0)^{\mathrm{a}}$ & $50.5(12.4)$ & $48.5(13.2)$ & .17 \\
Height $(\mathbf{c m})$ & $178.5(8.46)$ & $167.0(9.16)$ & $171.8(10.6)$ & - \\
Weight $(\mathbf{k g})$ & $104(24.8)$ & $99.1(26.8)$ & $105.7(25.8)$ & - \\
BMI $\left(\mathbf{k g} / \mathbf{m}^{\mathbf{2}}\right)$ & $32.4(5.99)$ & $35.6(9.5)$ & $34.3(8.34)$ & .12 \\
WC $(\mathbf{c m})$ & $107.7(25.5)$ & $103.0(22.1)$ & $104.9(22.1)$ & .39 \\
WHtR & $0.60(.09)$ & $0.62(0.15)$ & $0.61(.012)$ & .64 \\
\hline
\end{tabular}

Note: Body mass index; WC: waist circumference; WHtR: waist-to-height ratio

${ }^{\text {a }}$ Mean (standard deviation). $p$-value (male vs. female)

$* p<.05$, two-tailed

Table 2

Table of correlations

\begin{tabular}{lccc}
\hline Variable & BMI & WC & WHtR \\
\hline Resting [bLa] & .223 & .146 & .168 \\
Prime HR & -.218 & $-.301^{*}$ & $-.283^{*}$ \\
Anaerobic HR & -.164 & -.173 & -.175 \\
\hline
\end{tabular}

Note: $* \mathrm{p}<.05$, two-tailed. $\mathrm{n}=59$ 


\section{Table 3}

Demographics of DEXA participants

\begin{tabular}{llllc}
\hline Measurement & Men $(\mathbf{n = 6})$ & Women $(\mathbf{n = 9})$ & Total $(\mathbf{n = 1 5})$ & $\boldsymbol{p}$-value \\
\hline Age $(\mathbf{y e a r s})$ & $41.7(6.35)^{\mathrm{a}}$ & $55.33(9.12)$ & $49.9(10.49)$ & .679 \\
BMI $\left(\mathbf{k g} / \mathbf{m}^{\mathbf{2}}\right)$ & $30.9(7.20)$ & $31.0(5.56)$ & $30.9(6.01)$ & .088 \\
WC $(\mathbf{c m})$ & $102.8(13.64)$ & $97.4(11.98)$ & $99.6(14.47)$ & .221 \\
WHtR & $0.57(0.06)$ & $0.59(.09)$ & $0.58(.08)$ & .732 \\
BF\% & $31.7(2.99)$ & $42.8(8.35)$ & $38.4(8.64)$ & -- \\
\hline
\end{tabular}

Note: ${ }^{\mathrm{a}}$ Mean (standard deviation)

$p$ - value compares demographic of DEXA participant to demographics of all participants

Table 4

Table of correlations for DEXA participants

\begin{tabular}{lcccc}
\hline Variable & BMI & WC & WHtR & BF\% \\
\hline Resting [bLa] & .335 & .357 & .457 & .440 \\
Prime HR & -.312 & -.390 & -.350 & -.453 \\
Anaerobic HR & -.341 & -.350 & -.228 & -.395 \\
\hline
\end{tabular}

Note: $* p<.05$, two-tailed. $\mathrm{n}=15$ 


\section{Figure 1}

Body Mass Index (BMI) and Resting Blood Lactate Concentration

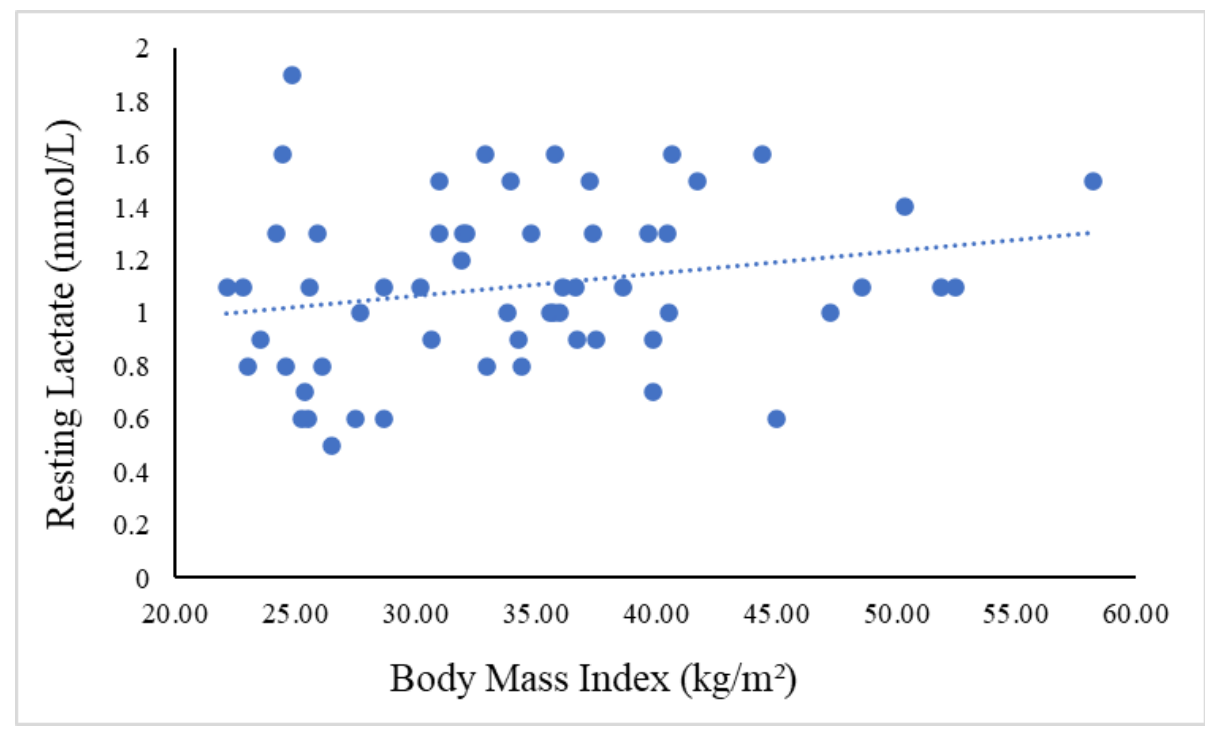

Note: No statistically significant correlation. $\mathrm{n}=59$

\section{Figure 2}

Body Mass Index (BMI) and Prime Heart Rate $\left(P R_{H R}\right)$

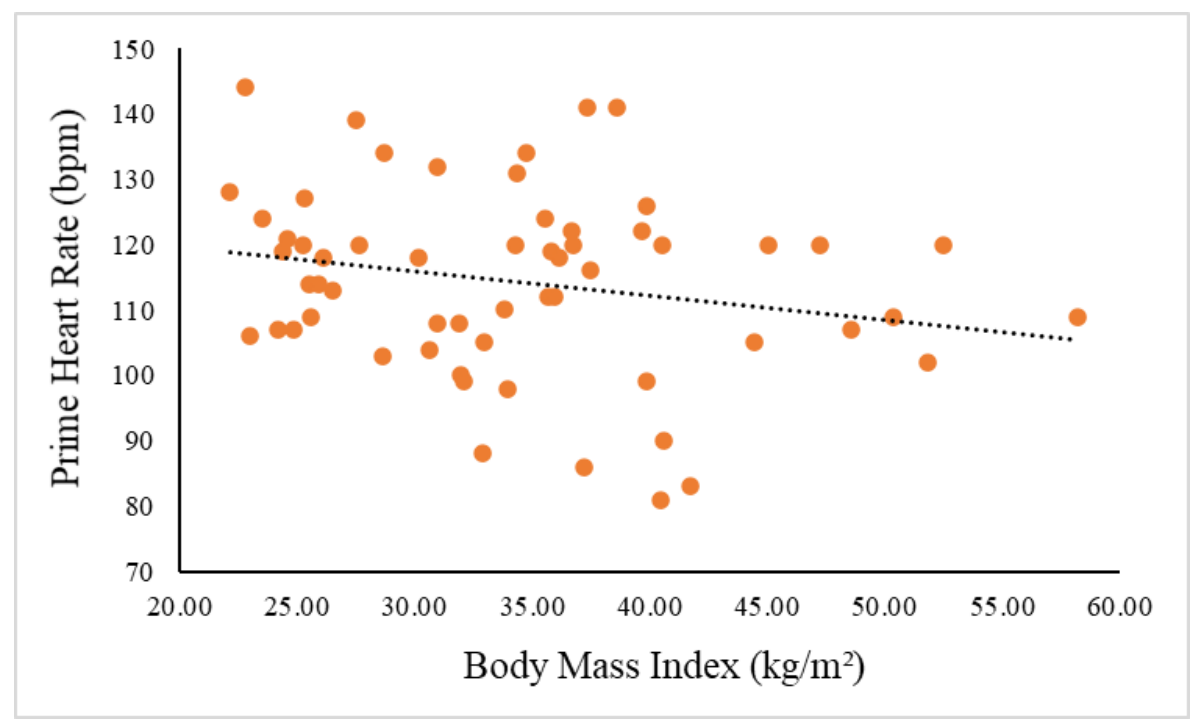

Note: No statistically significant correlation. $\mathrm{n}=59$ 


\section{Figure 3}

Body Mass Index (BMI) and Anaerobic Heart Rate (AN $\left.{ }_{H R}\right)$

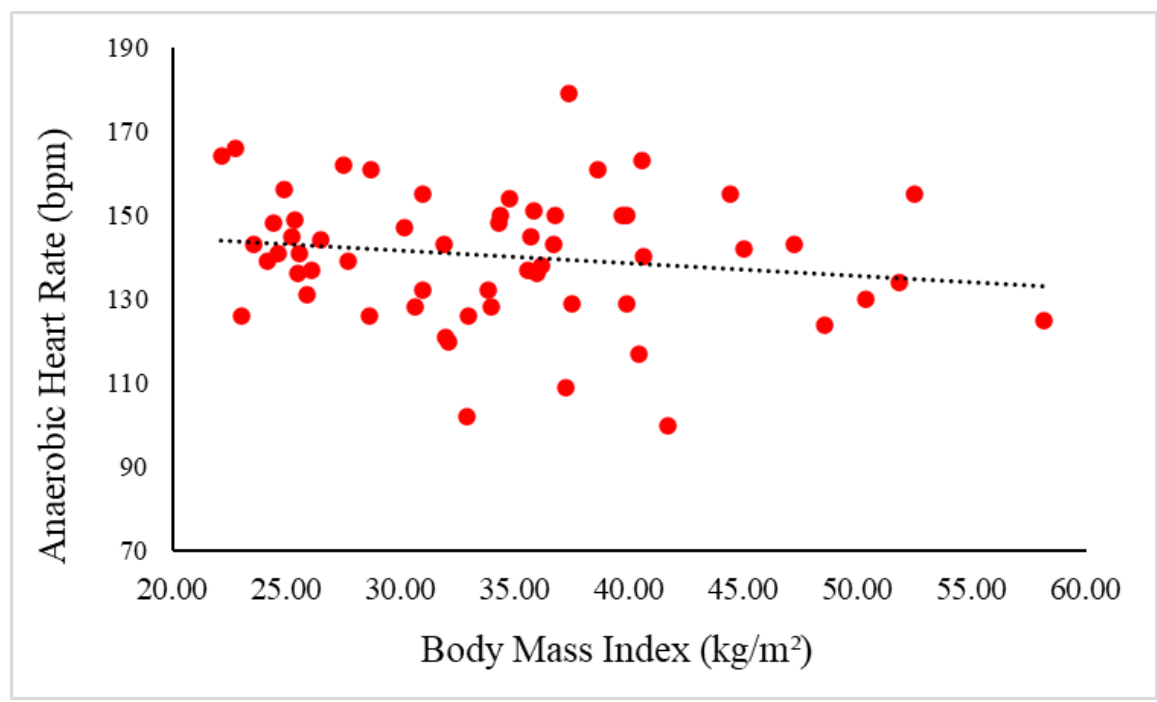

Note: No statistically significant correlation. $\mathrm{n}=59$

\section{Figure 4}

Waist Circumference (WC) and Resting Blood Lactate Concentration

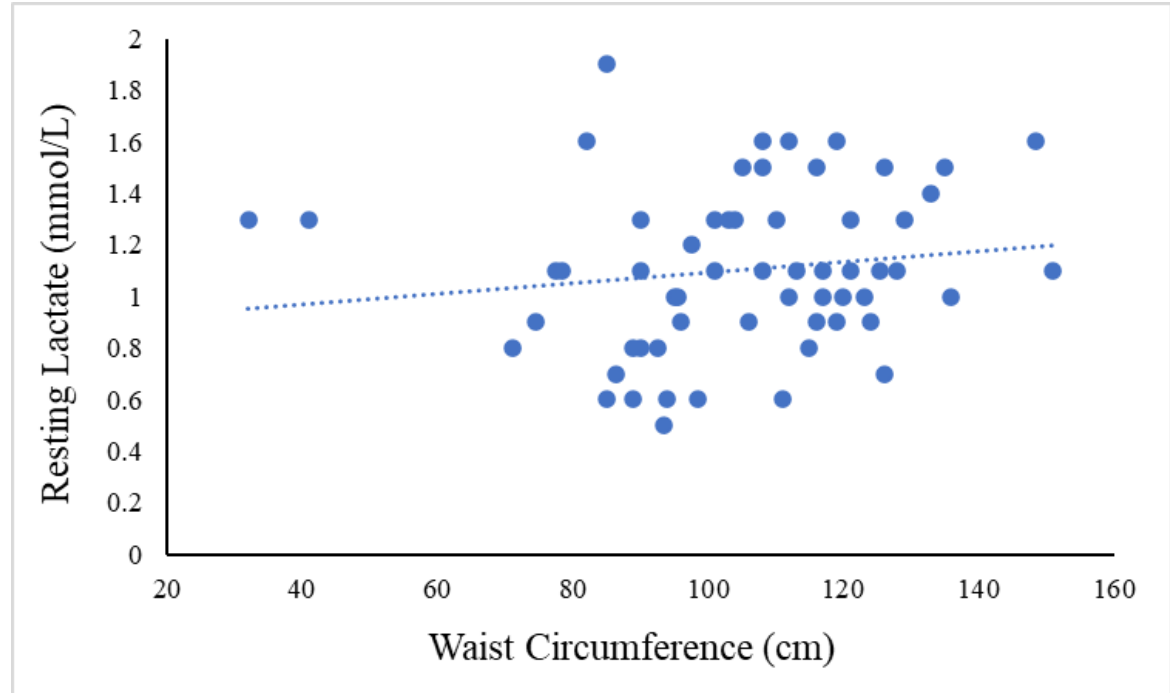

Note: No statistically significant correlation. $\mathrm{n}=59$ 


\section{Figure 5}

Waist Circumference (WC) and Prime Heart Rate $\left(P R_{H R}\right)$

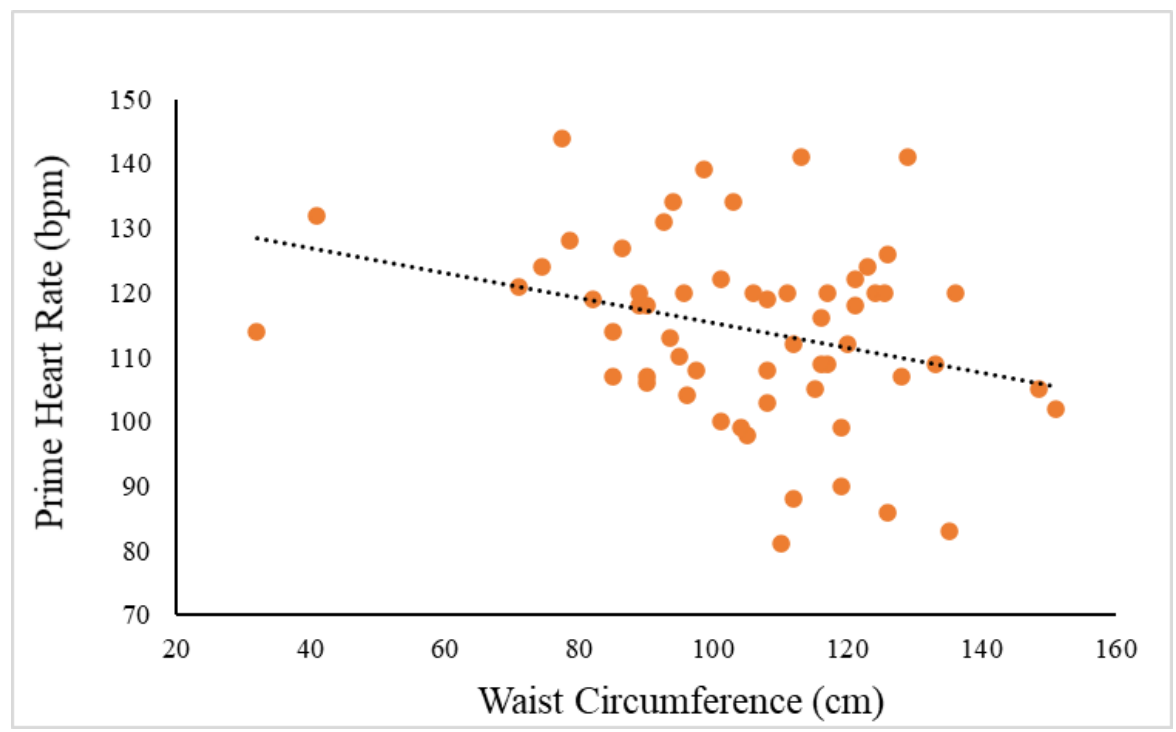

Note: $p=.02 . \mathrm{n}=59$

\section{Figure 6}

Waist Circumference (WC) and Anaerobic Heart Rate (AN $\left.N_{H R}\right)$

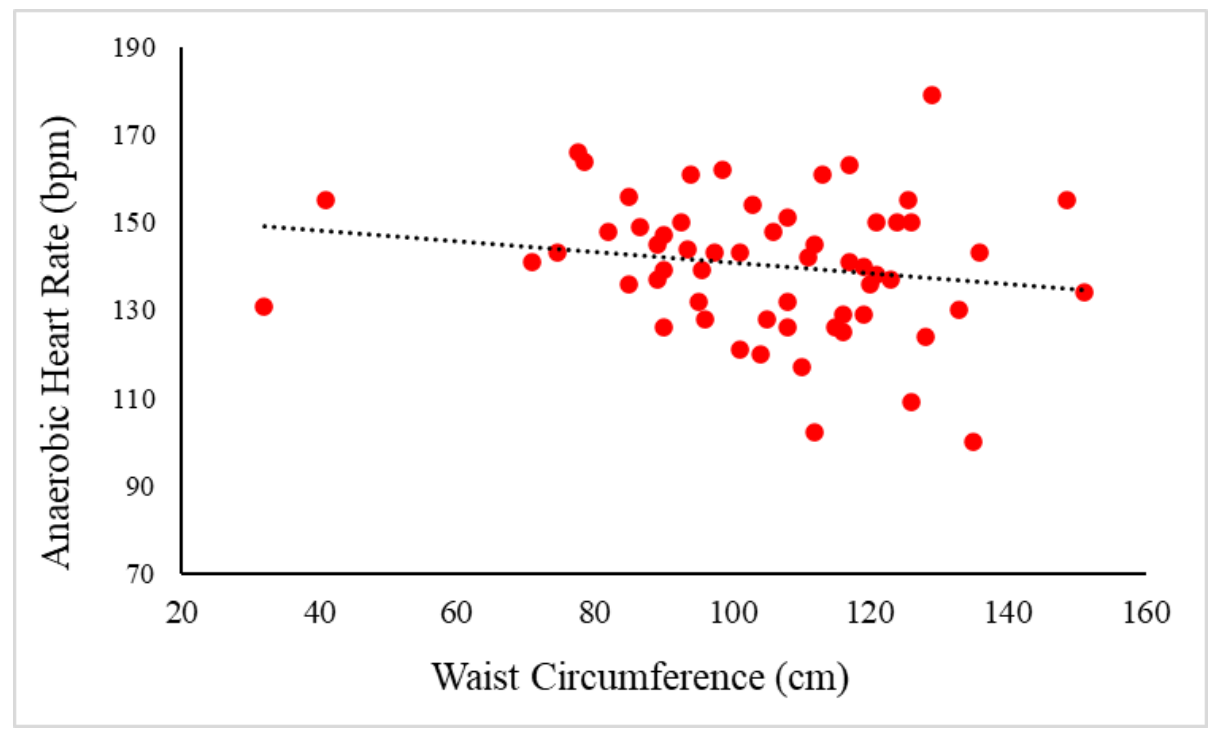

Note: No statistically significant correlation. $\mathrm{n}=59$ 


\section{Figure 7}

Waist to Height Ratio (WHtR) and Resting Blood Lactate Concentration

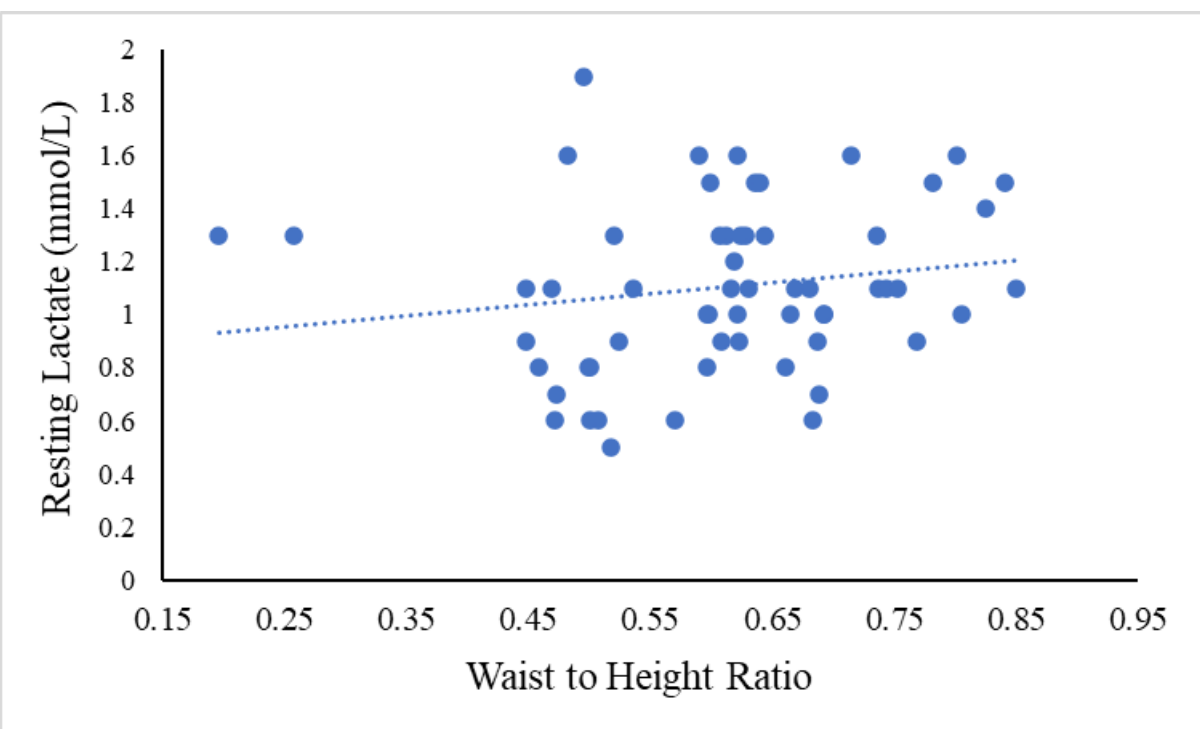

Note: No statistically significant correlation. $\mathrm{n}=59$

\section{Figure 8}

Waist to Height Ratio (WHtR) and Prime Heart Rate $\left(P R_{H R}\right)$

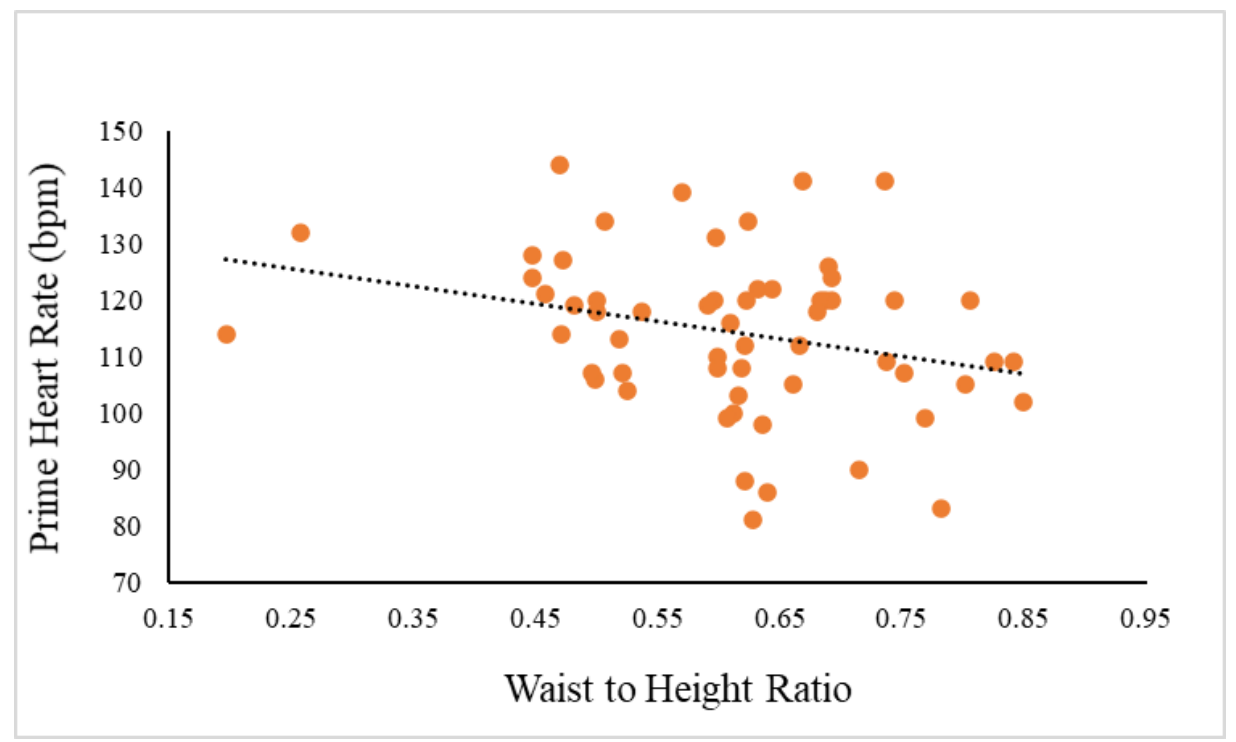

Note: $p=.03 . \mathrm{n}=59$ 


\section{Figure 9}

Waist to Height Ratio (WHtR) and Anaerobic Heart Rate (AN $\left.{ }_{H R}\right)$

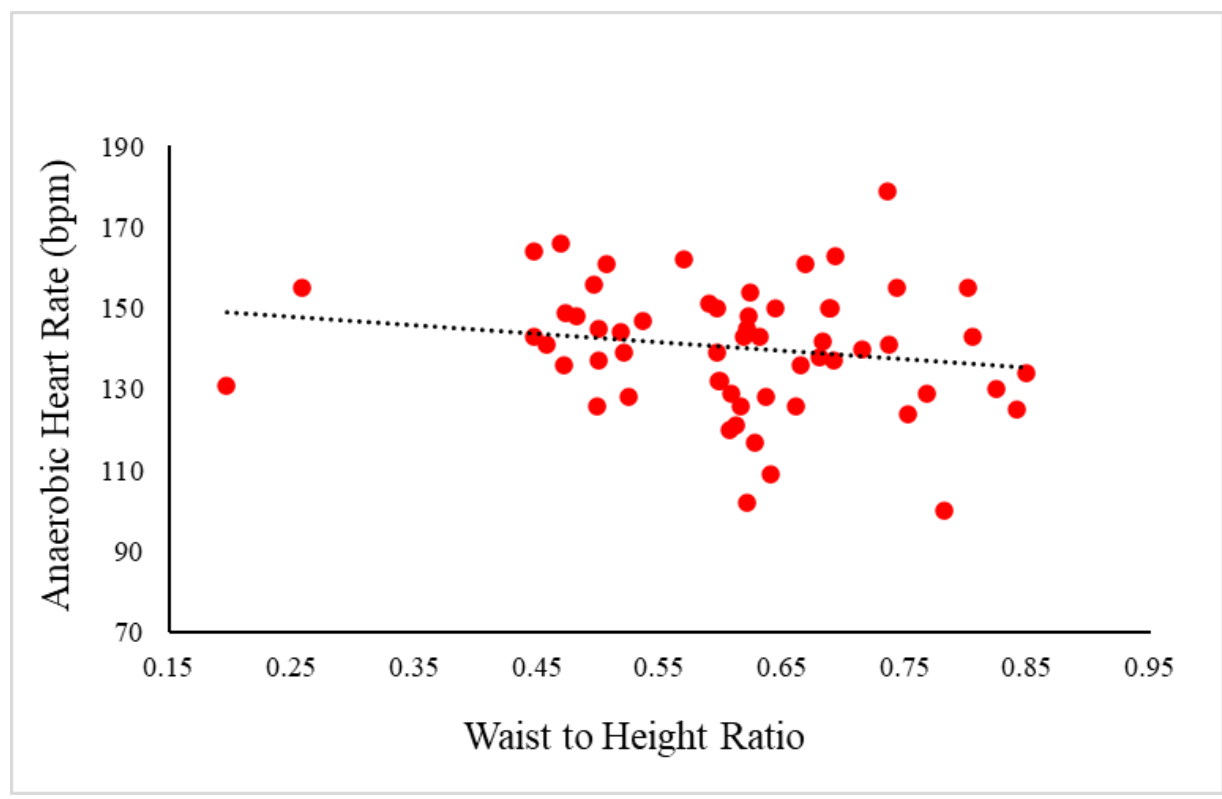

Note: No statistically significant correlation. $\mathrm{n}=59$

\section{Figure 10}

Body Fat Percent (BF\%) and Resting Blood Lactate Concentration

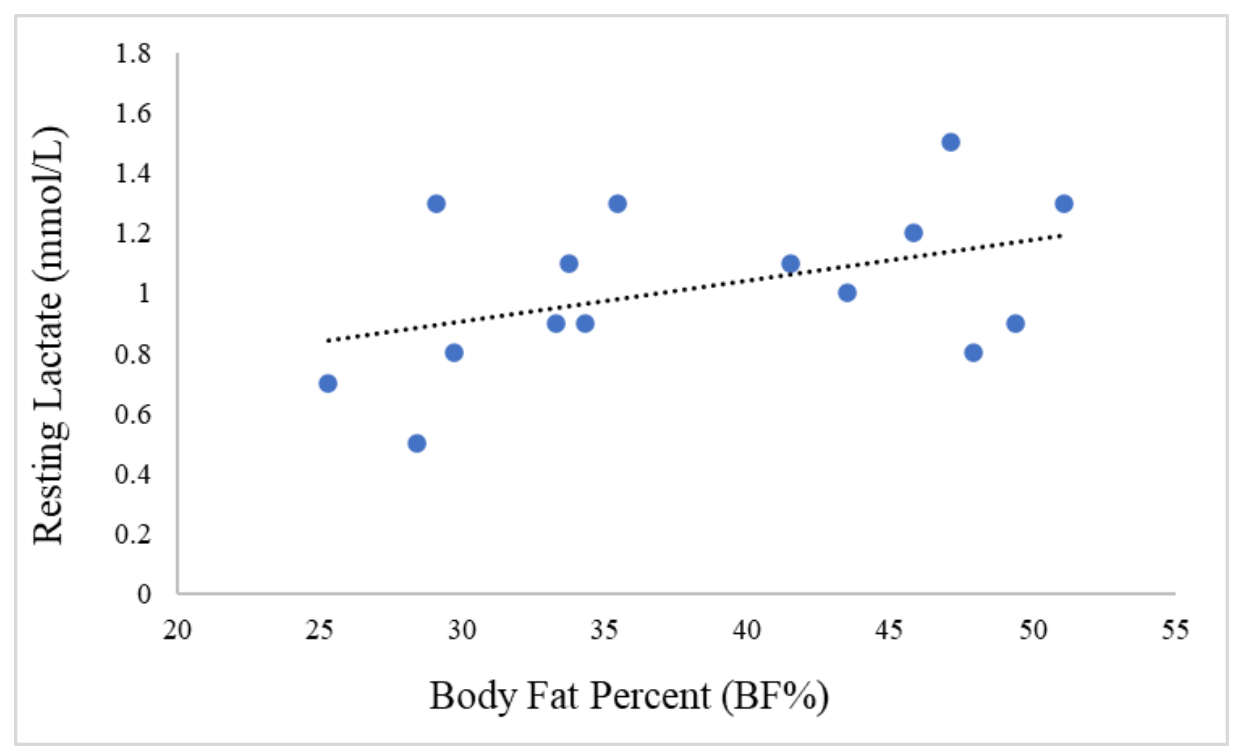

Note: No statistically significant correlation. $\mathrm{n}=15$ 


\section{Figure 11}

Body Fat Percent (BF\%) and Prime Heart Rate (PRHR)

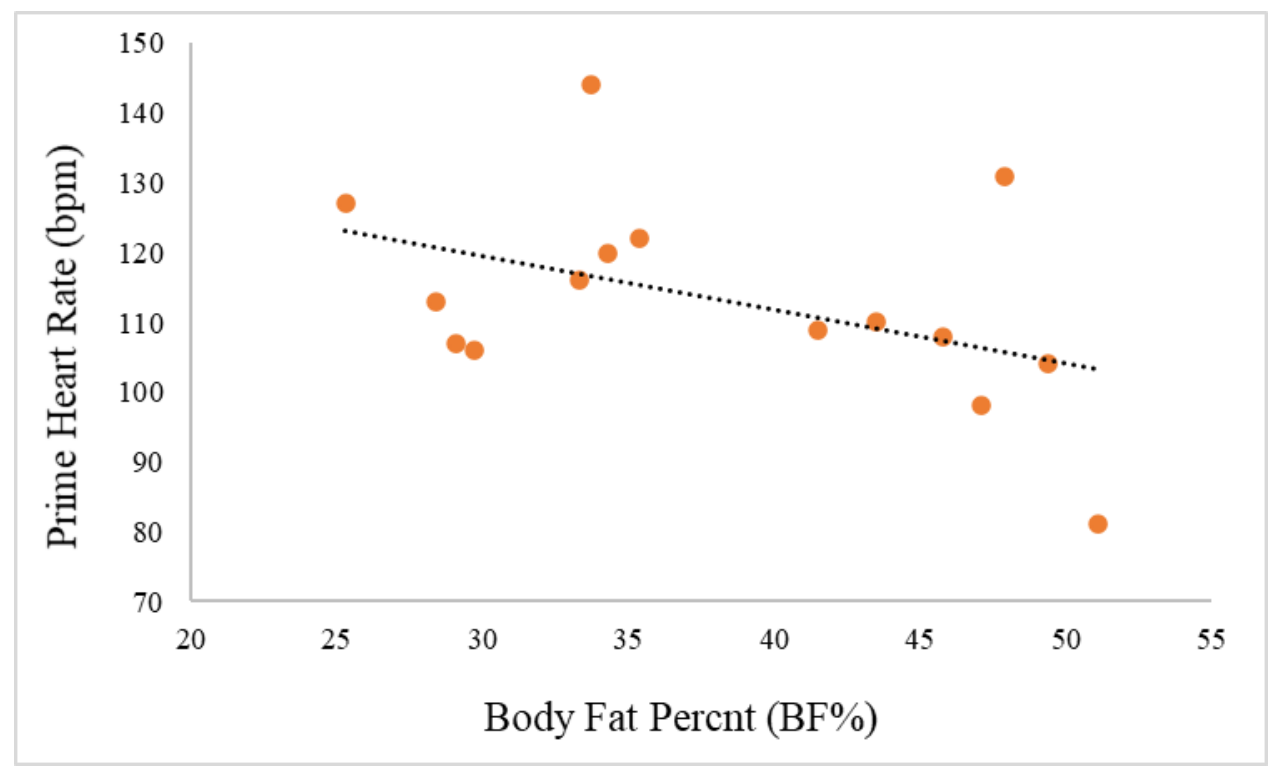

Note: No statistically significant correlation. $\mathrm{n}=15$

\section{Figure 12}

Body Fat Percent (BF\%) and Anaerobic Heart Rate (ANHR)

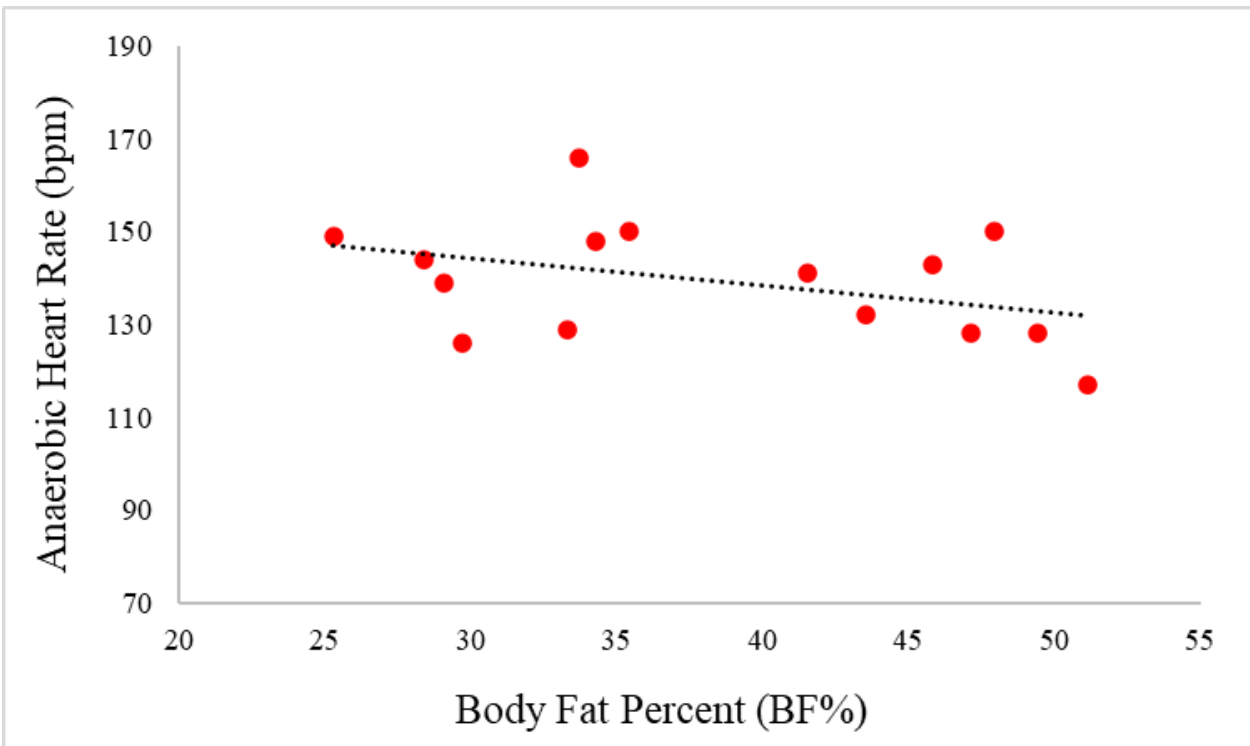

Note: No statistically significant correlation. $\mathrm{n}=1$ 


\section{CHAPTER II: REVIEW OF THE LITERATURE}

\section{Anthropometric Measurement Accuracy and Relationship to Health-Related Outcomes}

Anthropometric measurements are quantitative measurements often used in both clinical and community settings to assess the composition of the body. The foundation of anthropometric measures include height, weight, body mass index (BMI), body circumferences, and skinfold thicknesses. These measurements provide insight on overall adiposity and the distribution of adipose on the body. They are frequently used criteria for diagnosis and are often correlated with negative health related outcomes when values are outside the recommended range. For the context of the study, the anthropometrics that will be examined are BMI, waist circumference (WC), waist-to-height ratio (WHtR), and body fat percentage (BF\%).

\section{Body Mass Index (BMI)}

BMI is the most widely used and accepted method to assess weight status. An individual is classified as underweight if they have a BMI below $18.5 \mathrm{~kg} / \mathrm{m}^{2}$. A normal or healthy weight is classified as a BMI between 18.5 and $24.9 \mathrm{~kg} / \mathrm{m}^{2}$. A BMI of $25.0-29.5 \mathrm{~kg} / \mathrm{m}^{2}$ is considered overweight, while a BMI of $30.0 \mathrm{~kg} / \mathrm{m}^{2}$ or greater is considered obese. An elevated BMI is associated with various health risks including hypertension, stroke, diabetes, dyslipidemia, and other metabolic disorders (Ashwell et al., 2012).

\section{Body Fat Percentage}

There are several methods for estimating BF\%. Skinfolds are a cost-effective widely used method for evaluating body fatness (Lohman \& Milliken, 2020). By measuring skinfolds from several different select locations of the body, at least three different sites, an estimation of BF\% can be made with a standard error or estimate (SEE) of three-to-four percent (Lohman \& Milliken, 2020). Circumferences may also be used to predict BF\% by using the appropriate 
equation for age and sex. For instance, in women, the abdomen, thigh and forearm circumference can be used to estimate BF\% (Lohman \& Milliken, 2020). Bioelectrical impedance analysis (BIA) is yet another method for estimating BF\%. BIA measures the impedance of an electrical current sent through the body and calculates $\mathrm{BF} \%$ from an estimated fat free mass. BIA is an accepted field method and has a SEE of roughly three-and-a-half to five percent (Lohman \& Milliken, 2020). Dual energy x-ray absorptiometry (DEXA) is a laboratory method predominately used to measure bone density but may also be used to determine BF\%. DEXA is more accurate when compared to other field methods for determining BF\% with a SEE of twoto-three percent (Lohan \& Milliken, 2020).

BMI is often associated with BF\%. In general, the higher the BMI of an individual, the larger BF\% an individual may possess (Vanavanan et al., 2018). Unfortunately, BMI does not paint a full picture regarding BF\% or overall adiposity distribution (Vanavanan et al., 2018). In fact, some studies have evidence supporting that some BMI classified normal-weight individuals are actually at a higher risk than some BMI-classified overweight individuals for cardiovascular and metabolic diseases (Ashwell et al., 2012). One reason for this discrepancy is related to central adiposity stores. Central adiposity, or fat stored around your abdomen, increases pressure on vital internal organs and negatively impacts overall health and physical performance (Mahan et al., 2012). However, BMI fails to estimate adipose distribution.

Several studies have indicated individuals classified as normal-weight by BMI standards, actually have obese-level body fat percentages. One study analyzed the relationship between BF\% and BMI in in 1571 overweight and obese Nigerians of different ethnic groups. In those sampled in the study, nearly $10 \%$ of those BMI classified as overweight or obese had low BF\% highlighting the possibility for misclassification (Akindele et al., 2016). It has also been 
discussed that BMI is a poor measure of adiposity in the elderly as muscle mass declines and adipose stores increase. In a data set of 4984 men and women 60 and older, researchers found roughly $30 \%$ were classified as having obesity based on BMI standards (Batsis et al., 2016). When body fat was measured via DEXA, nearly $88 \%$ were classified as being obese (Batsis et al., 2016). Unfortunately, BMI can both overestimate and underestimate body fat percentage preventing health care professionals from accurately determining those at increased risk.

\section{Waist Circumference}

WC can be more indicative of body fat distribution and central adiposity. WC is an easily obtained field measurement taken around the waist and allows evaluation of central fat distribution. Men and women are classified as having a very high health risk when WC values are greater than 102 or 88 centimeters, respectively (Lohman \& Milliken, 2020; Matsuzawa \& Despres, 2020). Several studies have shown WC to be a stronger predictor for risk of developing cardiovascular disease than BMI across age and ethnic groups (Fan et al., 2016; Prabhu \& Kumar, 2019; Tran et al., 2018). This risk is predominantly attributed by the increased abdominal and visceral fat storage causing greater inflammation and pressure on internal organs and various contributions to metabolism. Elevated WC in older adults is also associated with a lower quality of life and decreased physical function (Batsis et al., 2014).

Evidence shows that both BMI and WC have been increasing disproportionately among populations. In other words, the expected WC for a given BMI has become higher than seen in previous years in the US, England, China, Mexico, and Canada (Albrecht et al., 2015; Janssen et al., 2012). To put this in perspective, research in a Canadian population found Canadians had a larger WC in 2007 than in 1981 (Albrecht et al., 2015). The WC in men increased by 1.1 centimeters, while women's WC increased by 4.9 centimeters for a BMI of $25 \mathrm{~kg} / \mathrm{m}^{2}$ (Albrecht et 
al., 2015). This is concerning as it would indicate that people are storing more abdominal adipose tissue at a given BMI than in previous years. These findings show flaws with solely using BMI to determine body fat and increased health risks as it fails to detect the increase in abdominal obesity which poses a greater health risk. Even though WC provides a better idea of adiposity distribution, other measures are needed to provide the full view.

\section{Waist to Height Ratio (WHtR)}

Another field method growing in popularity is WHtR. WHtR can provide a better picture of adiposity distribution in relation to stature and may be a stronger indicator of adverse health risk than WC and BMI. A waist to height ratio between $43-52 \%$ is indicative of a healthy weight (Lohman \& Milliken, 2020). However, a waist to height ratio less than $43 \%$ may be indicative of underweight status, while a ratio above $53 \%$ is indicative of an increased risk for metabolic diseases. One systematic review and meta-analysis concluded that WHtR was a better predictor for several metabolic risk factors when compared to BMI and WC (Ashwell et al., 2012). Furthermore, another study in Han Chinese population concluded WHtR was the best anthropometric measurement for predicting metabolic syndrome in obese, and non-obese adults (Yang et al., 2017).

\section{Body Fat and DEXA}

Adiposity can be more directly measured via dual energy x-ray absorptiometry (DEXA) scans which provide an overall $\mathrm{BF} \%$. Healthy ranges of $\mathrm{BF} \%$ vary with age and ethnicity, generally around $10-22 \%$ for men and $20-32 \%$ for women to reduce health risks associated to being overfat or underfat (Akindele et al., 2016; McArdle et al., 2015). Although WC and WHtR provide an easily obtained evaluation of central fat stores, it is only an estimation and does not consider genetic variation in body build (Okosun et al., 2015). The DEXA, however, is accurate 
in determining $\mathrm{BF} \%$ with variations of one to two percent and a standard error of estimate of two to three percent when compared to other multicomponent models (Lohman \& Milliken, 2020).

\section{Anthropometrics and Exercise Performance}

\section{BMI and Exercise Performance}

Having a high BMI also has negative consequences on the body's overall physical fitness and ability to perform exercise. Various studies have shown negative correlations between BMI and aerobic fitness measures such as maximum oxygen consumption $\left(\mathrm{VO}_{2 \max }\right)$, lactate threshold, and anaerobic threshold (Modal \& Mishra, 2017; Silva et al., 2011). One study by Silva et al. (2011) evaluated $\mathrm{VO}_{2 \max }$ and $\mathrm{BMI}$ in 66 sedentary women in three different categories: normal weight, overweight, and obese. The researchers found the obese group to not only have the lowest relative $\mathrm{VO}_{2 \max }$ results, but they also reported a higher rate of perceived exertion indicating that the test was much more difficult for them to complete (Silva et al., 2011).

Another study in obese individuals aimed to assess the ventilatory threshold and lactate threshold in obese and normal weight women and how weight loss would affect thresholds (ZakGolab et al., 2010). Researchers found the obese group to have a higher lactate threshold than the control group; however, when in relation to body weight and fat free mass, lactate levels were lower in the obese group. Researchers hypothesized this was attributed to the decreased tissue glucose consumption seen in insulin resistance, often noted in obesity, paired with an increased use of free fatty acids for a fuel source (Zak-Golab et al., 2010). When related to fat free mass, it was noted that ventilatory threshold was significantly lower in obese than normal weight women. After a three-month weight loss program and weight loss of $12 \%$, there were no significant changes in either threshold (Zak-Golab et al., 2010). It appears obesity may cause higher lactate 
thresholds overall, however, lactate thresholds are lower in the obese than someone of normal weight when corrected for fat free mass.

Unfortunately, the study did not report what the weight loss consisted of in terms of body fat and fat free mass. This study lends a better understanding of threshold values in obese, something that is not heavily studied. This study also noted that oxygen consumption during exercise was higher in obese than normal-weight women due to the increased demands needed to move a larger mass. Overall, those with a higher BMI are not able to perform aerobic exercises as efficiently and may have a more difficult time exercising than their normal-weight counterparts.

\section{Abdominal Adiposity and Exercise Performance}

Additionally, studies have shown WC to be more strongly negatively correlated with physical performance and overall fitness than BMI (Dyrstad et al., 2019; Kang et al., 2011; Mikkola et al, 2018; Shioya-Yamada et al., 2018; Tran et al., 2018). In a study conducted by Dyrstad et al. (2019) 722 participants were separated into risk categories based on WC then underwent a graded treadmill test to measure maximal oxygen uptake. The aim was to determine if there were significant differences in cardiorespiratory fitness and WC. There were three WC groups based on men and women WC respectively: normal risk (WC $>94$ and $<80 \mathrm{~cm}$ ) high risk (WC 94-102 and 80-87 cm), and very high risk (WC>102 and >87 cm). Researchers reported no significant differences in daily physical activity between the groups. There was a high negative correlation between $\mathrm{WC}$ and cardiorespiratory fitness in men, and a moderate correlation in women. Furthermore, for each one-centimeter increase in WC, cardiorespiratory fitness decreased by $0.48 \mathrm{~mL} / \mathrm{kg} / \mathrm{min}$ in men and $0.27 \mathrm{~mL} / \mathrm{kg} / \mathrm{min}$ in women (Dyrstad et al., 2019). This indicates just how much abdominal adiposity can impact exercise performance. To further attest 
to abdominal obesity's impact on exercise performance, another study investigated visceral fat accumulation and exercise tolerance in non-obese subjects and found visceral fat volume to be a significant determinate for decreased exercised tolerance (Shioya-Yamada et al., 2018).

\section{Metabolically Healthy Obese and Metabolically Obese Normal Weight}

There are several concepts that are trending but are not yet fully understood or widely accepted. The first is the metabolically healthy obese (MHO). This is the idea that you can be classified as obese via BMI, yet you do not have, or show, any metabolic irregularities or complications. Alternatively, there are individuals who can be classified as metabolically obesenormal weight (MONW) persons. MONW are those who are classified as normal weight via BMI yet display metabolic irregularities that may contribute to metabolic syndrome similar to what is seen in obesity. Another concept that should not be confused with MHO are those who are "fit but fat" (FBF). Individuals who are FBF care categorized as obese via BMI, but have high cardiovascular fitness levels (Duncan, 2010). These concepts overall show that there is more to the picture than just someone's BMI when it comes to fitness and metabolic health.

The prevalence of MHO adults is difficult to determine. A systematic review and meta-

analysis revealed nearly one third of obese individuals are considered metabolically healthy (Lin et al., 2017). However, researchers stress that these individuals are still at risk for metabolic related health issues. The idea of MHO is not widely accepted. Although there may appear to be a large population that is MHO, one longitudinal study lends a different view. A study conducted by Bell et al. (2015) followed healthy-obese adults for 20-years. In the study's sample, nearly half of adults classified at MHO transitioned into a metabolically unhealthy state by the end of the 20-year follow up. This study may show that MHO is only temporary, with the negative effects of obesity possibly "catching up" to individuals down the road. 
Several studies have investigated the prevalence of MONW. A study conducted in 2004 by St-Onge et al. investigated the rates and likelihood of metabolic syndrome in individuals who were classified as normal weight and slightly overweight (BMI of $18.5-26.9 \mathrm{~kg} / \mathrm{m}^{2}$ ) using National Health and Nutrition Examination Survey (NHANES) data from 1988-1994. The metabolic variables used included blood pressure, serum triglyceride, glucose, and waist circumference. Researchers found the overall prevalence of metabolic syndrome ranges from $17.5 \%$ to $30.6 \%$ depending on sex and ethnicity. A similar study was conducted in Korea with data from 8987 non-diabetic participants over the age of 40 years collected between 2003-2006 (Lee et al., 2001). The researchers used data on anthropometrics, lipid profiles, and a model for insulin resistance to determine metabolic syndrome. They also used a narrower definition of healthy weight with BMI ranging from 18.5 to $23.5 \mathrm{~kg} / \mathrm{m}^{2}$. The results showed the prevalence of MONW was $14.2 \%$ in men and $12.9 \%$ in women studied. With these results, it is plausible that a percentage of normal-weight individuals without a previous disease diagnosis may be experiencing metabolic syndrome, or metabolic-syndrome like symptoms effecting their overall lactate metabolism similar to their obese and diabetic counterparts.

One researcher analyzed the FBF concept in order to estimate the amount of people who are obese, but still have a high cardiovascular fitness level (Duncan, 2010). The researcher analyzed data from the NHANES (1999-2002) of adults who completed a submaximal exercise test. After utilizing sex and age-specific criteria from the Aerobics Center Longitudinal Study, $8.9 \%$ of adults in this study met the definition of FBF. The study also shown that $17.4 \%$ were classified as overweight based on BMI yet had a high cardiovascular fitness level. Some BMI misclassification can be due to high lean body mass experienced in some athletes who focus on building muscle, but this group is a small proportion of the overall population as a whole. The 
key point is someone can still have a fit cardiovascular system and sustain exercise even if they are obese or overweight.

\section{Role of Lactate in the Body}

After more than one hundred years of investigation, the full extent of lactate's metabolic role in the body is not yet fully understood. Lactate was once thought to simply be a metabolic waste product. It was also thought that lactate was the culprit of muscle soreness and fatigue after exercise. However, lactate's role in the body is much more complex. Lactate contributes to both energy storing and energy producing metabolic pathways. Lactate is formed in various organs and muscles, is a factor in glucose metabolism, can be used as fuel, and may play a larger role than previously thought in cognitive function (Proia et al., 2016; McArdle et al., 2017). In order to better understand its role during exercise, we must first investigate its role as a whole in the body.

\section{Lactate Formation}

Simply put, life is fueled by the molecule adenosine triphosphate (ATP). The energy it takes to run a mile, type a paper, or even blink an eye is provided by ATP. All cellular processes are driven by the energy released when ATP is hydrolyzed. ATP can be generated from several different pathways. Glycolysis is the metabolism of primarily glucose into two molecules of pyruvate, two net ATP, and two protonated nicotinamide adenine dinucleotide (NADH) molecules. In aerobic conditions, the two pyruvates will be converted into acetyl coenzyme A (Acetyl CoA) and enter the tricarboxylic acid cycle (TCA cycle). The TCA cycle will produce substrates that will ultimately undergo oxidative phosphorylation and produce more ATP. Pyruvate may also be reduced by lactate dehydrogenase into lactic acid which quickly dissociates into lactate and a hydrogen ion $\left(\mathrm{H}^{+}\right)$. This process allows the reformation of essential 
reducing agents required for glycolysis. In the absence of oxygen (anaerobic), the oxidative phosphorylation pathway slows down, causing an accumulation of substrates which upregulates the production of lactate via pyruvate dehydrogenase.

It is important to understand that lactate is produced continuously at rest. Anaerobic metabolism continues at a steady rate throughout the day as some cells, such as red blood cells and renal cells, lack the mitochondria necessary for oxidative phosphorylation (Petto et al., 2011). These cells still need to produce energy, and therefore utilize anaerobic metabolism to make ATP. At rest, [bLa] is typically around $1.0-2.0 \mathrm{mmol} / \mathrm{L}$ (Fraude et al., 2009).

\section{Lactate Accumulation During Exercise}

Lactate is a product of anaerobic metabolism that is produced both at rest and during exercise if skeletal muscle is not receiving enough oxygen. Lactate does not necessarily start to accumulate during all intensities of exercise. At low intensity exercise, or exercising at less than $50 \%$ aerobic capacity, lactate generally is not produced at a faster rate than it can be cleared (McArdle et al., 2017). Exercise at these intensities can be fueled adequately with ATP produced via oxidative phosphorylation. This utilization of aerobic energy systems during low-intensity exercise is why $[\mathrm{bLa}]$ trends near resting levels allowing an individual to maintain exercise for extended periods of time (McArdle et al., 2017; Moxnes \& Sandbakk, 2012).

During intense exercise, the body is unable to maintain a steady rate of aerobic metabolism causing lactate production to exceed the body's ability to clear lactate. Lactate starts to accumulate around 50-55\% of the maximal capacity for aerobic metabolism (McArdle et al., 2017). The point of physical activity where the body can no longer sustain clearance of lactate and lactate starts to accumulate in blood and muscles is termed lactate threshold. This point also indicates the point in physical activity where the body can no longer fuel exercise using aerobic 
metabolism and must shift to anaerobic metabolism. At this time, [bLa] can exceed upwards of 10-20 mmol/L (Fraude et al., 2009). Anaerobic energy systems cannot produce ATP rapidly enough to maintain high levels of exercise for long periods of time. Therefore, as [bLa] increases, exercise performance declines.

\section{Lactate as an Energy System Indicator}

Since lactate increases exponentially during graded exercise as the body switches to anaerobic metabolism, the $[\mathrm{bLa}]$ can indicate which is the predominant energy system at a certain point in exercise. A [bLa] of $2 \mathrm{mmol} / \mathrm{L}$ is considered an aerobic threshold maker (Bircher et al., 2005; Fraude et al., 2009; Spurway, 1992). Athletes typically perform around this [bLa] during endurance events (Spurway, 1992). Whereas a [bLa] of $4 \mathrm{mmol} / \mathrm{L}$ can be considered an anaerobic threshold marker (Bircher et al., 2005; Fraude et al., 2009; Grant et al., 2002; Petto et al, 2011; Schmid et al., 1998). In other words, at a [bLa] of $4 \mathrm{mmol} / \mathrm{L}$, anaerobic metabolism is predominating, limiting the time in which an athlete or individual will be able to sustain exercise at that level. Recent studies have evidence supporting a [bLa] of $4 \mathrm{mmol} / \mathrm{L}$ to be a reliable predictor for anaerobic threshold (Grant et al., 2002; Heuberger et al., 2018). In short, if we know the heart rate (HR) a subject is exercising at to produce a [bLa] of $2 \mathrm{mmol} / \mathrm{L}$, then we can theorize that if they continue at that HR, they can maintain aerobic exercise.

\section{Lactate and Fatigue}

As previously mentioned, lactate used to take the blame for fatigue during exercise. The increase in acidity is caused by the dissociation of lactic acid, produced from pyruvate, into lactate and $\mathrm{H}^{+}$(Nalbandian \& Takeda, 2016; Proia et al., 2016). It is now generally accepted that fatigue, muscle cramps, and decrease in performance is related to this acid build up in the blood and working tissues (Nalbandian \& Takeda, 2016; Proia et al., 2016). It appears that an acidic 
environment impairs muscles from contracting normally, causing discomfort, and preventing an individual from maintaining exercise at this level for a prolonged time (Moxnes \& Sandbakk, 2012; Proia et al., 2016). Interestingly, the acidic environment may also inhibit enzymes of glycogenolysis (glycogen may also be used as a fuel) and glycolysis, further decreasing the body's ability to produce adequate ATP for exercise (Proia et al., 2016). In summary, exercising at a [bLa] indicative of anaerobic exercise will prevent an individual from exercising for extended periods of time due to fatigue and lack of energy supply.

\section{Lactate Clearance}

Lactate's complex role in the body also means there are a variety of ways the body can work to clear lactate or maintain steady lactate levels. Lactate can be used as a fuel. When lactate is taken up by the liver or kidneys it can undergo gluconeogenesis. Gluconeogenesis is the production of glucose from non-carbohydrate substrates (Mahan et al., 2012; McArdle et al., 2017). Once converted to glucose, it can be used to produce energy. Lactate can also be cleared and utilized by both exercising and non-exercising muscles, the brain, and the heart as an energy source (Chen et al., 2017; McArdle et al., 2017). In addition, isotope tracer studies have shown that some muscle cells are able to convert lactate to pyruvate that was produced in other muscle cells (McArdle et al., 2017). The pyruvate can then undergo aerobic metabolism via TCA cycle and oxidative phosphorylation (McArdle et al., 2017). This is the process of lactate shuttling in which lactate may be transported into the mitochondria or peroxisomes to be oxidized (McArdle et al., 2017; Proia et al., 2016). This provides fuels for other cells created via glycogenolysis in another cell. This also means that muscle not only contributes to the accumulation of lactate, but also contributes to removal of lactate through oxidation (McArdle et al., 2017). It may also be converted into glycogen to be stored for energy in the future (McArdle et al., 2017). When the 
liver, heart, and muscles cannot clear lactate as quickly as it is produced, lactate starts to accumulate. The hormones epinephrine and norepinephrine also play a role in clearance. These hormones can cause a decrease in the use of oxidative pathways (McArdle et al., 2017; Proia et al., 2016). It is important to note that most lactate clearance routes require aerobic metabolic pathways which cannot run at full capacity during anaerobic exercise conditions. An individual can also increase their ability to clear lactate through exercise (Fukuba et al., 1993). The more aerobically fit an individual is, the lower their lactate is likely to be during low to moderate exercise.

\section{Metabolic Diseases and Disorders Impact on Lactate}

\section{Adipose Tissue and Lactate}

There is evidence to support the idea that adipocytes can produce lactate when there is not adequate oxygen available (Proia et al., 2016). Under anaerobic conditions, adipocytes can use glycolytic metabolism to produce lactate proportional to the amount of adipose tissue (Perez de Heredia et al., 2010; Proia et al., 2016). This means that the more adipose tissue you have, or the higher $\mathrm{BF} \%$, the more lactate you may produce in anaerobic conditions. BF\% can range from three to five percent in trained athletes, up to 60-70\% in severely obese individuals (Digirolamo et al., 1992). It is also interesting to note the observation of different rates of lactate production by adipocytes depending on their location in the body. Mesenteric adipose tissue, or fat storage around the intestines, are included in visceral adipose tissue (VAT) otherwise known as central adipose tissue. These cells have been found to have greater rates of glucose to lactate metabolism that is two to three times greater than other depots (Digirolamo et al., 1992). Individuals with greater $\mathrm{BF} \%$, or larger $\mathrm{WC}$, may experience higher levels of lactate than their leaner, lower WC, 
counterparts. It may then be concluded that someone with a higher BF\% would reach their lactate threshold quicker than a leaner individual.

There is little research specifically on anthropometric data and lactate levels during exercise. One study by Sung et al. (2016) conducted in Korean college students investigated the relationship between [bLa] after all-out exercise and BF\%. Body fat was measured using bioelectrical impedance analysis and lactate was measured right after intense exercise and again after two, four, and six minutes of rest. The study included a healthy and unhealthy group according to BF\% with no significant differences in resting [bLa] between the groups. Participants with higher BF\% experienced higher [bLa] immediately after all-out exercise and experienced higher [bLa] post exercise than the healthy group (Sung et al., 2016). This is just one study, but it does show the potential relationship between $\mathrm{BF} \%$ and $[\mathrm{bLa}]$ during intense exercise. This relationship may also be explained by the idea that more adipose tissue is contributing to lactate production in the participants with a higher BF\%, causing higher levels of lactate post exercise. Additionally, even though these studies did not directly measure aerobic fitness, it could be concluded that individuals with cardiovascular deficiencies or metabolic complications would have a decreased overall fitness level which may hinder their ability to clear lactate efficiently.

A study conducted by Chen et al. in 2017 examined diet-induced obesity in rats and its effect on blood lactate accumulation during incremental exercise. Rats were fed either a standardized chow or a high-fat diet for 14 weeks. During the incremental treadmill test, blood lactate accumulated faster, and the running time was lower in the animals fed the high-fat diet when compared to the control group. The researchers also found decreased levels of lactate transporters and proteins responsible for lactate uptake and utilization in the liver in the obese 
group when compared to the control. Chet et al. (2017) concluded the decrease in exercise performance and increased [bLa] can be contributed to the changes in metabolism associated with obesity.

\section{Obesity and Resting Lactate}

Anthropometric measures and [bLa] have been weakly investigated in healthy individuals. However, resting [bLa] has been investigated more thoroughly in obese subjects. Increasing levels of obesity are associated with increased [bLa] as obesity alters lactate metabolism (Chondronikola et al., 2018). High resting [bLa] is also seen in individuals with type two diabetes and can serve as markers of insulin resistance (Chondronikola et al., 2018; Lovejoy et al., 1992). It has also been observed that weight loss can reduce resting [bLa] in type two diabetics (Chondronikola et al., 2018).

\section{Impaired Glucose Metabolism and Lactate}

Increased [bLa] may be an indicator of impaired glucose metabolism and the development of insulin resistance (Chondroikola et al., 2018; Lovejoy et al., 1992). In diabetes glucose metabolism is impaired. Studies have shown higher resting $[\mathrm{bLa}]$ in those with type two diabetes (Chondroikola et al., 2018; Crawford et al., 2010; Avogaro et al., 1996). It has also been noted that adipose cells in obese or diabetic individuals can metabolize $50-70 \%$ of their glucose uptake into lactate, which is more than what is seen in leaner individuals (Digirolamo et al., 1992). This may be contributing to the higher levels of resting [bLa]. Those with type two diabetes also do not see a decrease in fasting [bLa] with weight loss, which can be seen in people with obesity and metabolic syndrome (Chondroikola et al., 2018). Metabolic syndrome encompasses health issues such as high blood pressure, high blood sugar, diabetes, blood lipid levels, and excessive body fat (St-Onge et al., 2004; Freedland, 2004). The interactions between 
disruptive glucose metabolism and lactate production is one reason why studying the relationship between lactate and exercise is tricky in a diabetic population.

\section{Lactate Testing}

Lactate testing is a popular method of determining aerobic fitness in endurance athletes. These types of tests have been employed for decades providing athletes with personalized training intensities to maximize performance (Dantas \& Doria, 2015; Faude et al., 2009). The most common use of lactate testing is to determine the maximum lactate steady state (MLSS) and lactate threshold (LT). MLSS is the highest workload that can be maintained over a period of time without seeing a rise in [bLa] (Beneke et al., 2011). The LT describes the point at which blood lactate accumulates faster than the body can metabolize it (Ghosh, 2004). However, these tests are predominantly used in athletes and are not often used in untrained, general populations.

\section{Method CRA Testing}

Lactate testing has recently become more readily available to the general public. A Denver-based company offers Method Cellular Respiration and Analytics (CRA) test. This is an incremental test used to determine individualized heart rate zones based on [bLa]. This is a newer protocol that has not yet been extensively researched. The aim of this test is to maximize the benefits of exercising while also reducing the risk of injury. Method CRA testing measures both HR and [bLa] to determine HR ranges in which subjects are exercising aerobically or anaerobically. The tests provide three individualized heart rate zones: prime ( $\left.\mathrm{PR}_{\mathrm{HR}}\right)$, anaerobic (AN $\mathrm{HR}_{\mathrm{HR}}$, and peak ( $\left.\mathrm{PK}_{\mathrm{HR}}\right)$.

The $\mathrm{PR}_{\mathrm{HR}}$ zone is characterized as a blood lactate level of $2.0 \mathrm{mmol} / \mathrm{L}$ and is where the body is maximizing aerobic energy systems. Individuals can maintain exercise for extended periods of time and are most likely to see performance improvements when working at this HR 
zone. The $\mathrm{AN}_{\mathrm{HR}}$ is characterized as a blood lactate level of $4.0 \mathrm{mmol} / \mathrm{L}$ and is the point in which the body is oxidizing less fat and instead turning to carbohydrates as its main energy source. The $\mathrm{PK}_{\mathrm{HR}}$, not to be confused with a maximum $\mathrm{HR}$, is characterized as a [bLa] level of $6.0 \mathrm{mmol} / \mathrm{L}$. Exercise at this level cannot be sustained for a long time as the body is using any available carbohydrate sources and may resort to degrading muscle tissue to obtain fuel. 


\section{REFERENCES}

Akindele, M. O., Phillips, J. S., \& Igumbor, E. U. (2016). The relationship between body fat percentage and body mass index in overweight and obese individuals in an urban African Setting. Journal of Public Health in Africa, 7(1), 515.

https://doi.org/10.4081/jphia.2016.515

Albrecht, S. S., Gordon-Larsen, P., Stern, D., \& Popkin, B. M. (2015). Is waist circumference per body mass index rising differentially across the United States, England, China and Mexico? European Journal of Clinical Nutrition, 69(12), 1306 - 1312. https://doi.org/10.1038/ejcn.2015.71

American College of Sports Medicine (2018). ACSM's guidelines for exercise testing and prescription (10th ed.). Philadelphia, PA: Wolters Kluwer.

Ashwell, M., Gunn, P. \& Gibson, S. (2012). Waist-to-height ratio is a better screening tool than waist circumference and BMI for adult cardiometabolic risk factors: Systematic review and meta-analysis. Obesity Reviews, (13), 275-286. doi:10.1111/j.1467789X.2011.00952.x

Avogaro, A., Toffolo, G., Miola, M., Valerio, A., Tiengo, A., Cobelli, C., \& Del Prato, S. (1996). Intracellular lactate- and pyruvate-interconversion rates are increased in muscle tissue of non-insulin-dependent diabetic individuals. The Journal of Clinical Investigation, 98(1), 108-115. https://doi.org/10.1172/JCI118754

Batsis, J. A., Mackenzie, T. A., Bartels, S. J., Sahakyan, K. R., Somers, V. K., \& Lopez-Jimenez, F. (2016). Diagnostic accuracy of body mass index to identify obesity in older adults: NHANES 1999-2004. International Journal of Obesity, 40(5), 761-767. https://doi.org/10.1038/ijo.2015.243 
Batsis, J. A., Zbehlik, A. J., Barre, L. K., Mackenzie, T. A., \& Bartels, S. J. (2014). The impact of waist circumference on function and physical activity in older adults: Longitudinal observational data from the osteoarthritis initiative. Nutrition Journal, 13, (81). https://doi.org/10.1186/1475-2891-13-81

Bell, J. A., Hamer, M., Sabia, S., Singh-Manoux, A., Batty, G. D., Kivimaki, M. (2015). The natural course of healthy obesity over 20 years. Journal of the American College of Cardiology, 65(1). 101-102. https://doi.org/10.1016/j.jacc.2014.09.077.

Bircher, S., \& Knechtle, B. (2004). Relationship between fat oxidation and lactate threshold in athletes and obese women and men. Journal of Sports Science \& Medicine, 3(3), 174181. https://www.ncbi.nlm.nih.gov/pmc/articles/PMC3905300/

Bircher, S., Knechtle, B., \& Knecht, H. (2005). Is the intensity of the highest fat oxidation at the lactate concentration of $2 \mathrm{mmol} \mathrm{L}(-1)$ ? A comparison of two different exercise protocols. European Journal of Clinical Investigation, 35(8), 491-8. https://doi.org/10.1111/j.13652362.2005.01538.x

Chen, C. N., Liao, Y. H., Lin, S. Y., Yu, J. X., Li, Z. J., Lin, Y. C., Chang, G. J., Lin, C. H., \& Wong, A. (2017). Diet-induced obesity accelerates blood lactate accumulation of rats in response to incremental exercise to maximum. American Journal of PhysiologyRegulatory, Integrative and Comparative Physiology, 313(5), 601-607. https://doi.org/10.1152/ajpregu.00337.2016

Chondronikola, M., Magkos, F., Yoshino, J., Okunade, A. L., Patterson, B. W., Muehlbauer, M. J., Newgard, C. B. \& Klein, S. (2018), Effect of progressive weight loss on lactate metabolism: A randomized controlled trial. Obesity, 26(4), 683-688. https://doi.org/10.1002/oby.22129 
Crawford, S. O., Hoogeveen, R. C., Brancati, F. L., Astor, B. C., Ballantyne, C. M., Schmidt, M. I., \& Young, J. H. (2010). Association of blood lactate with type 2 diabetes: The atherosclerosis risk in communities carotid MRI study. International Journal of Epidemiology, 39(6), 1647-1655. https://doi.org/10.1093/ije/dyq126

Dantas, J. L., \& Doria, C. (2015). Detection of the lactate threshold in runners: What is the ideal speed to start an incremental test? Journal of Human Kinetics, 45, 217-224. https://doi.org/10.1515/hukin-2015-0022

Duncan, G. E. The "fit but fat" concept revisited: Population-based estimates using NHANES. International Journal of Behavioral Nutrition and Physical Activity, 7(47). https://doi.org/10.1186/1479-5868-7-47

Dyrstad, S. M., Edvardsen, E., Hansen, B. H., \& Anderssen, S. A. (2019). Waist circumference thresholds and cardiorespiratory fitness. Journal of Sport and Health Science, 8(1), 1722. https://doi.org/10.1016/j.jshs.2017.03.011

Fan, H., Li, X., Zheng, L., Chen, X., Lan, Q., Wu, H., Ding, X., Qian, D., Shen, Y., Yu, Z., Fan, L., Chen, M., Tomlinson, B., Chan, P., Zhang, Y., \& Liu, Z. (2016). Abdominal obesity is strongly associated with Cardiovascular Disease and its Risk Factors in Elderly and very Elderly Community-dwelling Chinese. Scientific Reports, 6, 21521. https://doi.org/10.1038/srep21521

Faude, O., Kindermann, W., \& Meyer, T. (2009). Lactate threshold concepts: How valid are they. Sports Medicine, 39(6), 469-490. https://doi.org/10.2165/00007256-20093906000003 
Freedland E. S. (2004). Role of a critical visceral adipose tissue threshold (CVATT) in metabolic syndrome: Implications for controlling dietary carbohydrates: a review. Nutrition \& Metabolism, 1(1), 12. https://doi.org/10.1186/1743-7075-1-12।

Fukuba, Y., Walsh, M. L., Morton, R. H., Cameron, B. J., Kenny, C. T. C., \& Banister, E. W. (1999) Effect of endurance training on blood lactate clearance after maximal exercise, Journal of Sports Sciences, 17(3), 239-248. https://doi.org/10.1080/026404199366145

Ghosh A. K. (2004). Anaerobic threshold: Its concept and role in endurance sport. The Malaysian Journal of Medical Sciences, 11(1), 24 - 36. https://www.ncbi.nlm.nih.gov/pmc/articles/PMC3438148/

Grant, S., McMillan, K., Newell, J., Wood, L., Keatley, S., Simpson, D., Leslie, K., \& FairlieClark, S. (2002). Reproducibility of the blood lactate threshold, 4 mmol (-1) marker, heart rate and ratings of perceived exertion during incremental treadmill exercise in humans. European Journal of Applied Physiology, 87(2), 159-166. https://doi.org/10.1007/s00421-002-0608-2

Heuberger J. A. A. C, Gal P., Stuurman F. E., de Muinck Keizer W. A. S. , Mejia Miranda Y, Cohen A. F. (2018). Repeatability and predictive value of lactate threshold concepts in endurance sports. PLoS ONE 13(11): e0206846. https://doi.org/10.1371/journal.pone.0206846

Janssen, I., Shields, M., Craig, C. L. and Tremblay, M. S. (2012). Changes in the obesity phenotype within Canadian children and adults, 1981 to 2007-2009. Obesity, 20: 916919. https://doi.org/10.1038/oby.2011.122 
Kang, S. M., Yoon, J. W., Ahn, H. Y., Kim, S. Y., Lee, K. H., Shin, H., Choi, S. H., Park, K. S., Jang, H. C., \& Lim, S. (2011). Android fat depot is more closely associated with metabolic syndrome than abdominal visceral fat in elderly people. PloS ONE, 6(11), e27694. https://doi.org/10.1371/journal.pone.0027694

Lee, S. H., Ha, H. S., Park, Y. J., Lee, J. H., Yim, H. W., Yoon, K. H., Kang, M. I., Lee, W. C., Son, H. Y., Park, Y. M. \& Kwon, H. S. (2011). Identifying metabolically obese but normal-weight (MONW) individuals in a nondiabetic Korean population: The Chungju metabolic disease cohort (CMC) study. Clinical Endocrinology, 75(4), 475-481. https://doi.org/10.1111/j.1365-2265.2011.04085.x

Lohman, T. G., \& Milliken, L. A. (2020). ACSMs body composition assessment. Champaign, IL: Human Kinetics.

Lovejoy, J., Newby, F. D., Gebhart, M., \& DiGiromao, M. (1992). Insulin resistance in obesity is associated with elevated basal lactate levels and diminished lactate appearance following intravenous glucose and insulin. Metabolism, 41(1), 22-27. https://doi.org/10.1016/00260495(92)90185-D

Mahan, L. K., Escott-Stump, S., \& Raymond, J. L. (2012). Krause's food \& the nutrition care process (13th ed.). St. Louis, MO: Elsevier.

Matsuzawa, Y., \& Despres, J. P. (2020). Waist circumference as a vital sign in clinical practice: A consensus Statement from the IAS and ICCR working group on visceral obesity. Nature Reviews Endocrinology, 16, 177-189. https://doi.org/10.1038/s41574-019-0310-7 
Mikkola, T. M., von Bonsdorff, M. B., Salonen, M. K., Simonen, M., Pohjolainen, P., Osmond, C., Perälä, M. M., Rantanen, T., Kajantie, E., \& Eriksson, J. G. (2018). Body composition as a predictor of physical performance in older age: A ten-year follow-up of the Helsinki Birth Cohort Study. Archives of Gerontology and Geriatrics, 77, 163-168. https://doi.org/10.1016/j.archger.2018.05.009

McArdle W. D., Katch F. I., Katch V. L. (2015). Exercise physiology: Nutrition, energy, and human performance (8th Ed.). Philadelphia, PA: Wolters Kluwer Health/Lippincott Williams \& Wilkins.

Mondal, H., \& Mishra, S. P. (2017). Effect of BMI, body fat percentage and fat-free mass on maximal oxygen consumption in healthy young adults. Journal of Clinical and Diagnostic Research, 11(6), 17-20. https://doi.org/10.7860/JCDR/2017/25465.10039

Moxnes, J. F., \& Sandbakk, O. (2012). The kinetics of lactate production and removal during whole body exercise. Theoretical Biology \& Medical Modelling, 9(7). https://doi.org/10.1186/1742-4682-9-7

Okosun, I. S., Seale, J. P., \& Lyn, R. (2015). Commingling effect of gynoid and android fat patterns on cardiometabolic dysregulation in normal weight American adults. Nutrition \& Diabetes, 5(5). https://doi.org/10.1038/nutd.2015.

Pérez de Heredia, F., Wood, I. S. \& Trayhurn, P. (2010). Hypoxia stimulates lactate release and modulates monocarboxylate transporter (MCT1, MCT2, and MCT4) expression in human adipocytes. European Journal of Physiology, 459, 509-518. https://doi.org/10.1007/s00424-009-0750-3 
Petto, J., de Jesus, J. B., Vasques, L. M., Pinheiro, R. L., Oliveira, A. M., Spinola, K. A., \& Silva, W. (2011). Resting blood lactate in individuals with sickle cell disease. Revista Brasileira de Hematologia e Hemoterapia, 33(1), 26-30. https://doi.org/10.5581/15168484.20110010

Prabhu, A. \& Kumar, R. (2019). Comparative study of waist circumference and body mass index in obese patients for the risk of developing coronary artery disease. International Archives of Integrated Medicine, 6(8), 65-69. https://journals.indexcopernicus.com/api/file/viewByFileId/764789.pdf

Ross, R., Neeland, I. J., Yamashita, S., Shai, I., Seidell, J., Magni, P., Santose, R. D., Arsenault, B., Cuevas, A., Hu, F. B., Griffin, B. A., Zambon, A., Barter, P., Fruchart, J. C., Eckel, R. H., Matsuzawa, Y., \& Despres, J. P. (2020). Waist circumference as a vital sign in clinical practice: A consensus statement from the IAS and ICCR working group on visceral obesity. Nature Reviews Endocrinology 16, 177-189. https://doi.org/10.1038/s41574-019-0310-7

Schmid, A., Huonker, M., Aramendi, J. F., Klüppel, E., Barturen, J. M., Grathwohl, D., SchmidtTrucksäss, A., Berg, A., \& Keul, J. (1998). Heart rate deflection compared to 4 mmol x 1 (-1) lactate threshold during incremental exercise and to lactate during steady-state exercise on an arm-cranking ergometer in paraplegic athletes. European Journal of Applied Physiology and Occupational Physiology, 78(2), 177-182. https://doi.org/10.1007/s004210050404 
Shioya-Yamada, M., Shimada, K., Nishitani-Yokoyama, M., Sai, E., Takeno, K., Tamura, Y., Watada, H., Kawamori, R., Daida, H., \& Kawai, S. (2018). Association between visceral fat accumulation and exercise tolerance in non-obese subjects without diabetes. Journal of Clinical Medicine Research, 10(8), 630 - 635. https://doi.org/10.14740/jocmr3403w

Silva, S. G., Elsangedy, H. M., Krinski, K., Roberston, R. J. (2011). Effect of body mass index at intensities spanning the ventilatory threshold. Perceptual and Motor Skills, 113(2), 575 88. https://doi.org/10.2466/06.09.15.PMS.113.5.575-588

Spurway, N. C. (1992). Aerobic exercise, anaerobic exercise and the lactate threshold. British Medical Bulletin, 480(3), 569 - 591. https://doi.org/10.1093/oxfordjournals.bmb.a072564

St-Onge, M. P., Janssen, I., \& Heymsfield, S. B. (2004). Metabolic syndrome in normal weight Americans: New definition of the metabolically obese, normal-weight individual. Diabetes Care, 27(9), 2222-2228. https://doi.org/10.2337/diacare.27.9.2222

Sung, D. J., So, W. Y., Choi, D. H., \& Jeong, T. T. (2016). Blood lactate levels after all-out exercise depend on body fat percentage in Korean college students. Iranian Journal of Public Health, 45(6), 817 - 819. https://www.ncbi.nlm.nih.gov/pmc/articles/PMC5026839/

Tran, N., Blizzard, C. L., Luong, K. N., Truong, N., Tran, B. Q., Otahal, P., Nelson, M., Magnussen, C., Gall, S., Bui, T. V., Srikanth, V., Au, T. B., Ha, S. T., Phung, H. N., Tran, M. H., \& Callisaya, M. (2018). The importance of waist circumference and body mass index in cross-sectional relationships with risk of cardiovascular disease in Vietnam. PloS One, 13(5). https://doi.org/10.1371/journal.pone.0198202 
Yang, H., Xin, Z., Feng, J. P., \& Yang, J. K. (2017). Waist-to-height ratio is better than body mass index and waist circumference as a screening criterion for metabolic syndrome in Han Chinese adults. Medicine, 96(39). https://doi.org/10.1097/MD.0000000000008192

Zak-Golab, A., Zahorska-Markiewicz, B., Langfort, J., Kocelak, P., Holecki, M., Mizia-Stec, K., Olszanecka-Glinianowicz, M., \& Chudek, J. (2010). The influence of weight loss on anaerobic threshold in obese women. Journal of Sports Science \& Medicine, 9(4), 564-571. https://www.ncbi.nlm.nih.gov/pmc/articles/PMC3761814/ 